\title{
Wind Turbines Control: Features and Trends
}

\author{
Ali Oudah ${ }^{1}$, Izzeldin I. Mohd ${ }^{2} \&$ A. Hameed ${ }^{3}$ \\ ${ }^{1,3}$ Faculty of Manufacturing Engineering, Pekan, 26600, University Malaysia Pahang, Malaysia \\ ${ }^{2}$ Faculty of Electrical \& Electronics Engineering, Pekan, 26600, Universiti Malaysia Pahang, Malaysia \\ Correspondence: Ali Oudah, Faculty of Manufacturing Engineering, Pekan, 26600, University Malaysia Pahang, \\ Malaysia. E-mail: mark6ge@ge.com
}

Received: August 11, 2014

Accepted: August 21, $2014 \quad$ Online Published: November 18, 2014

doi:10.5539/mas.v8n6p272

URL: http://dx.doi.org/10.5539/mas.v8n6p272

\begin{abstract}
Energy is the basis for economic development and it is important to have a reliable supply of energy for the sustainable development of any country. With the rapid growth of the global economy, the energy crisis is aggravating substantially. It is, therefore, of great interest to develop reliable renewable energy resources that can take up a relatively large proportion of the growing energy needs with the crucial features of energy security, environment protection and economic development. Since the beginning of the twenty first century, countries all over the world and international organizations have invested tremendous amount of funds for the development of new energy systems. As a competitor to the conventional energy sources, wind energy is considered to be an important source for a diversified energy portfolio, particularly, because it is a clean energy source with an inexhaustible supply. Wind energy has become one of the fastest growing renewable energy systems with promising prospects for large scale commercialization. We provide in this tutorial paper an overview brief of basic wind turbine energy control systems and an optimistic or reflective area in a recent industry developments and research in wind turbine control systems for more grid performance and frequency stability.
\end{abstract}

Keywords: modern techniques, wind turbine control, controllers, wind turbine industry, frequency stability

\section{Introduction}

Wind turbines are systems that take mechanical energy from the wind and convert it to electrical energy. Many types of wind turbines exist today, with variations in rotation axis, number of blades, control surfaces and generator type being among the most common differences between turbines in the industry. The most prevalent turbines studied in the controls literature are the 3-bladed, upwind, horizontal axis wind turbines (HAWTs). These turbines operate with a vertical plane arrangement of evenly spaced blades and an active yaw system to bring the rotor-blade plane perpendicular to the prominent wind direction. HAWTs are studied often primarily because of their dominance in the marketplace and their use of active controls (Pao \& K. E 2011). Wind turbines have become increasingly prevalent on the electric grid, and constitute one of the largest new sources of grid capacity in the United States in recent years. In 2011, wind power comprised 32\% of added grid capacity in the United States and $42 \mathrm{GW}$ of wind power capacity was added worldwide. Wind power has seen a cumulative investment of $\$ 95$ billion since the beginning of the 1980s in the U.S. Wind is estimated to account for 3.3\% of the supply of electricity generated in the U.S., and sees penetrations as high as $29 \%$ in Denmark. Along with this increase in prevalence, utility scale wind turbines are getting larger. The average hub height has increased by $45 \%$ and the average rotor diameter has increased by $86 \%$ since 1998 , and further increases are expected (R \& J 2012). With this increase in the prevalence of wind turbines, turbine control systems are becoming more important. Regional Independent Systems Operators (ISOs) are requiring more control over turbine functionality. ISOs require wind turbines to be an active part of keeping the quality and availability of electricity high. Maintaining grid voltage and frequency while reducing harmonics in current are objectives that require participation from all generators. Up until this point, wind turbines and farms were considered a negative load, and the rest of the system was responsible for following this highly variable resource. As turbines become a more vital part of the energy market, classifying them as a negative load and allowing the injection of any power is not feasible for sustaining grid quality (Jet al. 2012). 


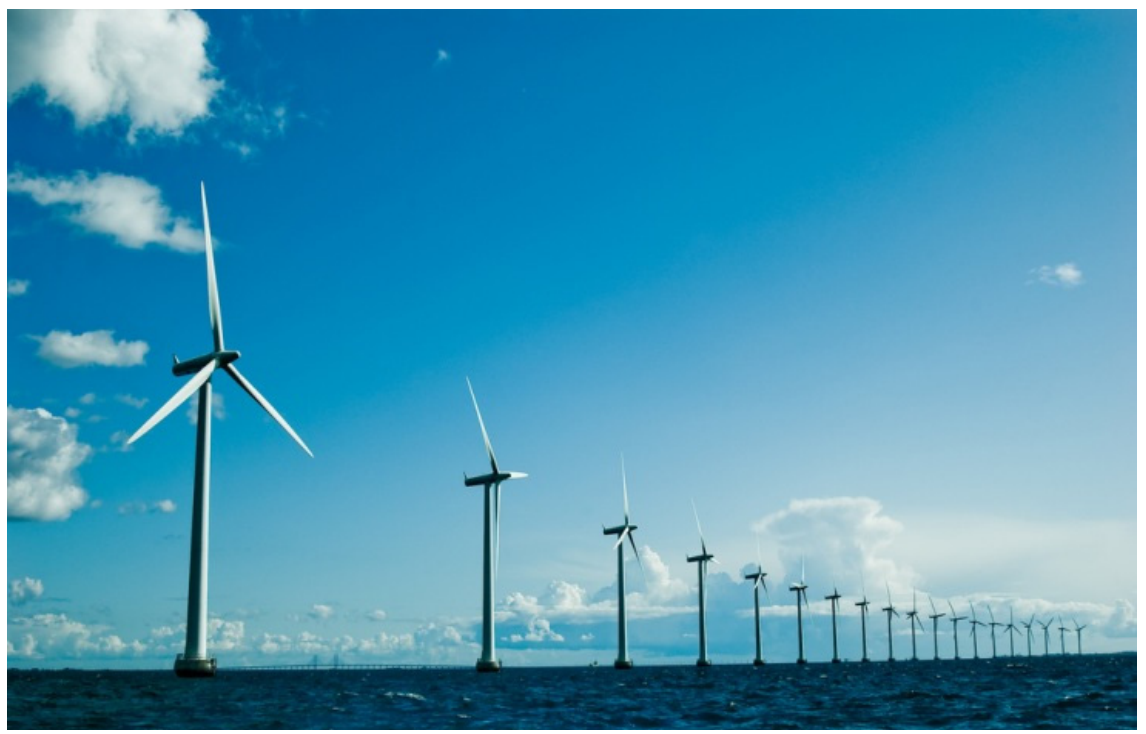

Figure 1. A row of turbines in a wind plant located in Alberta, CA. This wind plant contains 113 horizontal axis wind turbines (HAWTs), each rated at $660 \mathrm{~kW}$ with a rotor diameter of $48 \mathrm{~m}$ and hub height approx. $50 \mathrm{~m}$

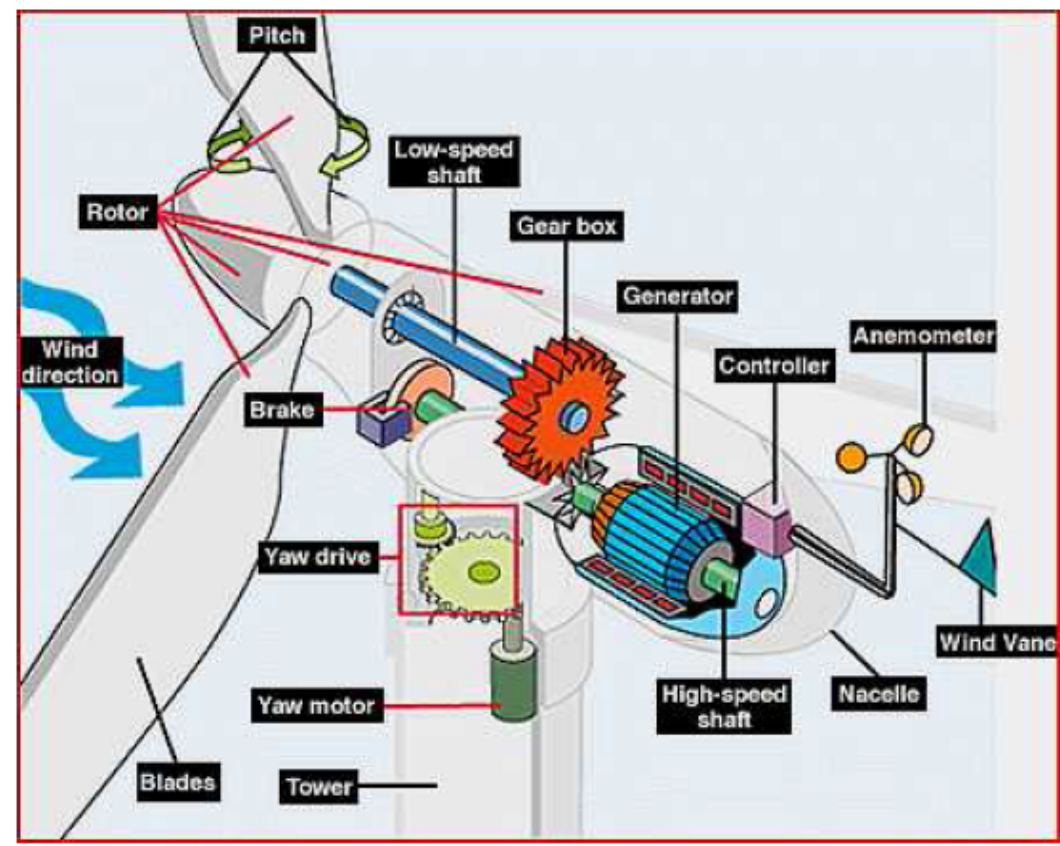

Figure 2. Illustration of a typical wind turbine setup (Molina and Alvarez, 2011)

Figure 2 shows a diagram of a typical horizontal axis wind turbine. The wind comes in perpendicular to the direction of the rotor plane, a direction which is actively controlled by the turbine yaw drive. The blades are allowed to pitch along their main axis, controlling the amount of lift that is generated from the wind. The torque created by the lift is transported down the low-speed shaft, then through a gearbox. The gearbox transforms the low rotational frequency to something high enough for optimal electrical generation in the generator. The nacelle sits at the top of the tower and provides the connection point to the rotor, as well as housing the generator, gearbox, and controller for the wind turbine. The anemometer and wind vane work together to provide wind speed and wind direction for the turbine controller.

\section{Wind Turbine Basics}

The power available in the wind with velocity $\mathrm{u}$ is given by 


$$
p_{\text {wind }}=\frac{1}{2} \rho \pi R_{a}^{2} u^{3}
$$

where is the air density $\rho$ and $\mathrm{R}_{\mathrm{a}}$ is the rotor radius. According to the Betz Limit, no turbine can extract more than $59.3 \%$ of the kinetic energy from the wind. $C_{P}$ is the power coefficient and is given by the ratio of the power captured by the rotor to the power available in the Wind, or

$$
C p==\frac{p_{\text {rotor }}}{p_{\text {wind }}}
$$

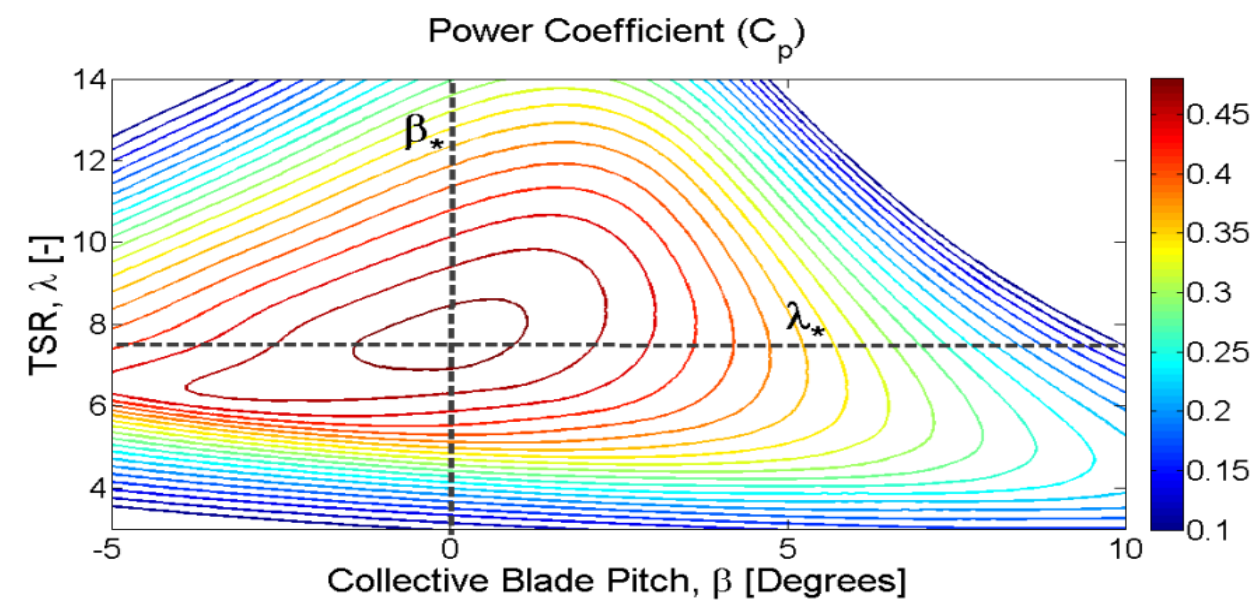

Figure 3. Cp versus TSR and blade pitch angle for the CART3. CART3's Cp-TSR-Pitch surface is fairly at close to its peak at a TSR of 5.8. The marked points indicate its peak and a sub-optimal design point with TSR of 7.1

$C_{P}$ is shown as a function of the tip-speed ratio (TSR) and blade pitch angle in Figure 1.1. TSR is dented as

$$
\lambda=\frac{\Omega}{u} R_{a}
$$

Where is the rotor speed. Wind turbines have either a vertical-axis or a horizontal-axis configuration. The horizontal axis configuration has been adopted widely for modern large wind turbines (Pao \& K. E 2011). As shown in Figure 2, for a horizontal-axis wind turbine (HAWT), the blades are connected to a low-speed drive shaft, and the high-speed drive shaft is connected to the generator. The low-speed and high-speed drive shafts are separated by a gearbox. The wind causes a lift force and subsequent torque on the blades to turn the rotor, and mechanical power is converted into electricity through the generator. The amount of energy captured by a wind turbine depends on the wind conditions. Generally, the turbine should be located in an area with abundant wind resources. Wind speed and wind direction are important parameters to characterize the wind profile, and they are measured using anemometers and wind vanes (Johnson et al. n.d.). Most modern turbines are variable pitch and variable-speed, which smooth's power actuations and reduce the drive train mechanical stress compared to older constant-speed, constant-pitch turbines. Variable-speed turbines allow for maximized capture of energy during partial load operation in conjunction with control systems (Muljadi \& Buttereld 2000)\&(Arnaltes 2003). The aerodynamic torque aero exerted on a turbine's rotor is given by

$$
\tau_{\text {aero }}=\frac{1}{2} \rho \pi R_{a}{ }^{3} \frac{c p}{\lambda} u^{2}
$$

For a turbine to operate at a constant rotor speed $\Omega$, the generator torque $\tau_{\mathrm{c}}$ must be equal to the aerodynamic torque aero $\tau_{\text {aero }}$. When $\tau_{\text {aero }}>\tau_{\mathrm{c}}$, the turbine will accelerate and vice versa.

$$
J_{T} \dot{\Omega}=\tau_{\text {aero }}-\lambda_{C}
$$

Where JT is the equivalent combined moment inertia of the rotor, the gear box, the low-speed shaft (LSS) and the high-speed shaft (HSS). Three operating regions are dented in Figure 2.3 ( $\mathrm{H}$ et al. 2006). 


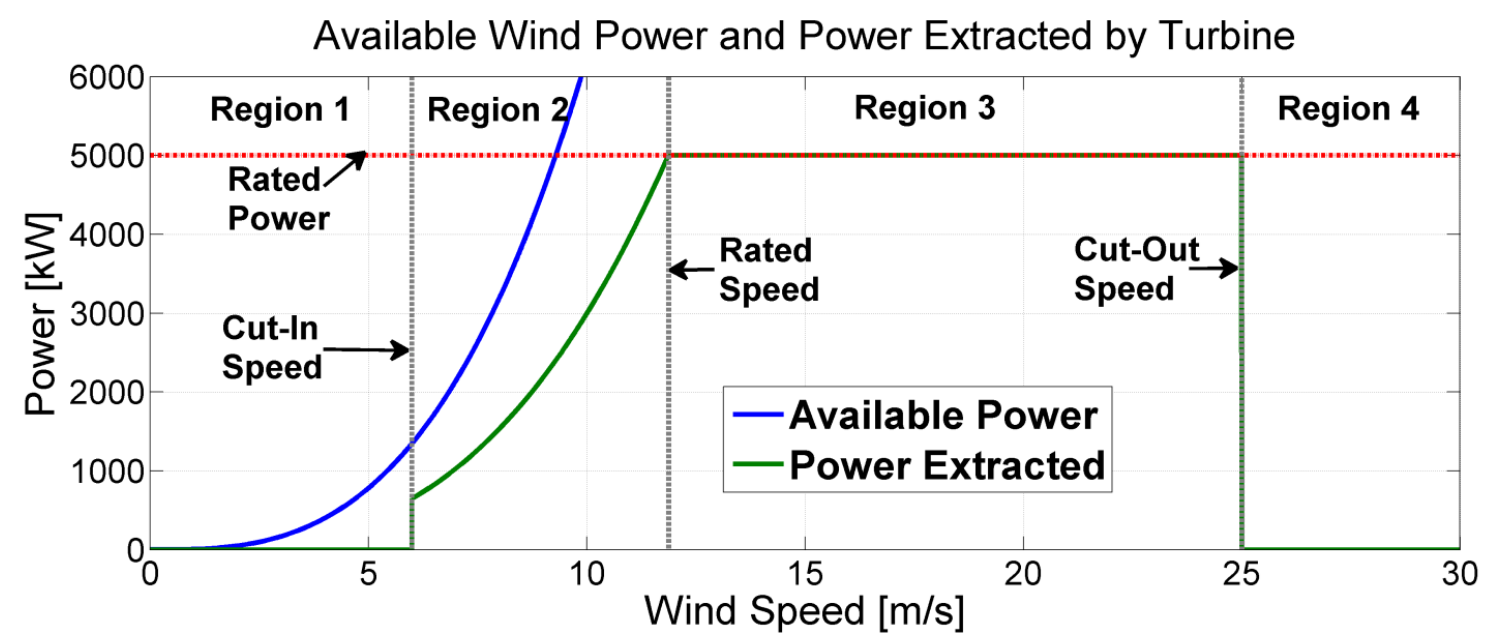

Figure 4. Power curve and generator torque curve for the CART3 (Anon n.d.)

In Region 1, the wind speed is so low that starting up wind the turbine is not worthwhile. Once the wind speed reaches a turbine-specie minimum, which is often between $3-5 \mathrm{~m} / \mathrm{s}$, the machine will start up. In Region 2, the wind speed is below rated, which is the value at which the turbine reaches its maximum power output and is usually in the vicinity of $12 \mathrm{~m} / \mathrm{s}$. In this region, the wind turbine is designed to capture as much power as possible by adjusting the generator torque to optimize power coefficient. Since rotor power is given by the product of available power (1.1) and power coefficient (1.2), the generated power increases according to a cubic law with wind speed assuming no energy loss in either the gearbox or generator. In Region 2, pitch angle is often controlled to the constant value that gives maximum Cp. In Region 3, as shown in Figure.4, the wind speed is above rated. The rotor speed and generator power should be limited to their rated values to avoid mechanical and electrical component damage. Generator torque is often held at rated and blade pitch angle is used to limit aerodynamic power by regulating turbine speed to the rated speed. Load mitigation on the blades and tower should be considered in this region. A control system consists of sensors, actuators, and compensators. The control objectives are denoted according to the turbine's operating regions.

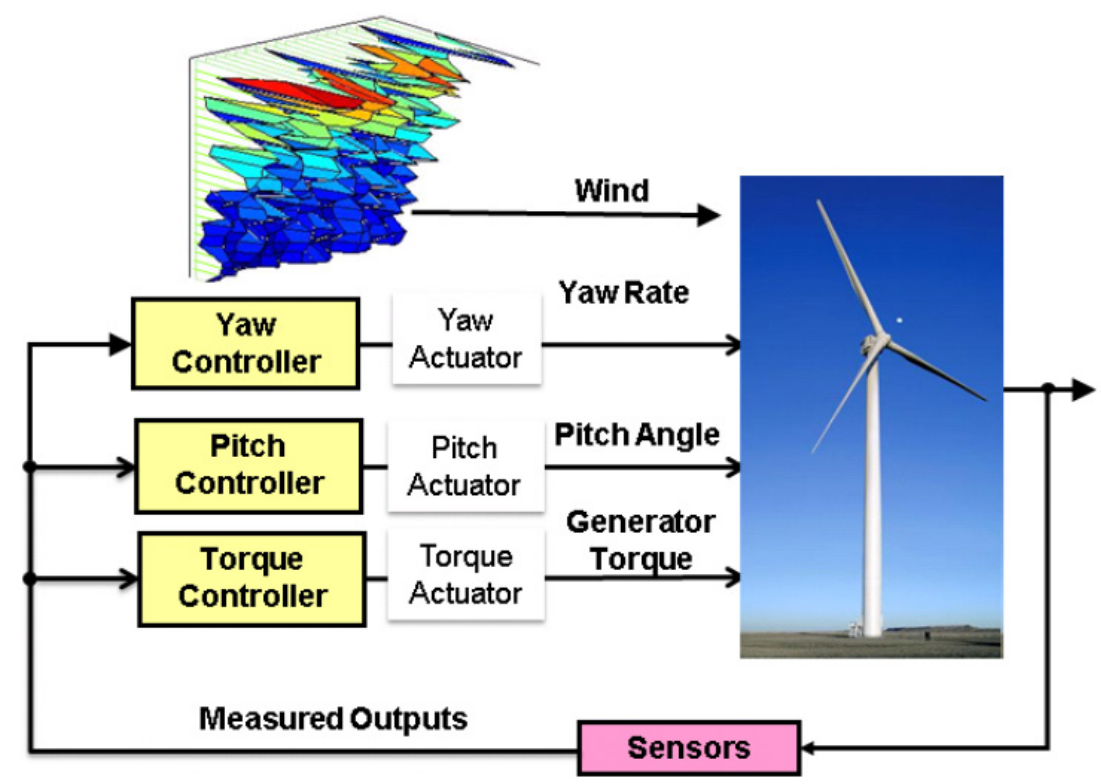

Figure 5. A wind turbine control block diagram. In this configuration, measured turbine speed is used in the pitch and torque feedback loops, while yaw error obtained from a wind direction sensor is utilized for the yaw control loop. Adapted from a gure in (Pao \& K. E 2011)

In Region 3, as shown in Figure .4, the wind speed is above rated. The rotor speed and generator power should 
be limited to their rated values to avoid mechanical and electrical component damage. Generator torque is often held at rated and blade pitch angle is used to limit aerodynamic power by regulating turbine speed to the rated speed. Load mitigation on the blades and tower should be considered in this region. A control system consists of sensors, actuators, and compensators. The control objectives are denoted according to the turbine's operating regions. The basic structure of the wind turbine control loops is shown in Figure.4. Current commercial wind turbine pitch control algorithms are typically feedback only. Though the details of modern utility-scale turbine control algorithms are proprietary and closely protected by industry, until recently most feedback controllers have been fairly straightforward proportional-integral (PI) based collective blade pitch controllers. These controllers typically operate on an input signal such as the error in rotor speed (or power) in Region 3 wind conditions. In this paper, a PI collective blade pitch controller shown in Figure .6 was selected as the baseline controller,

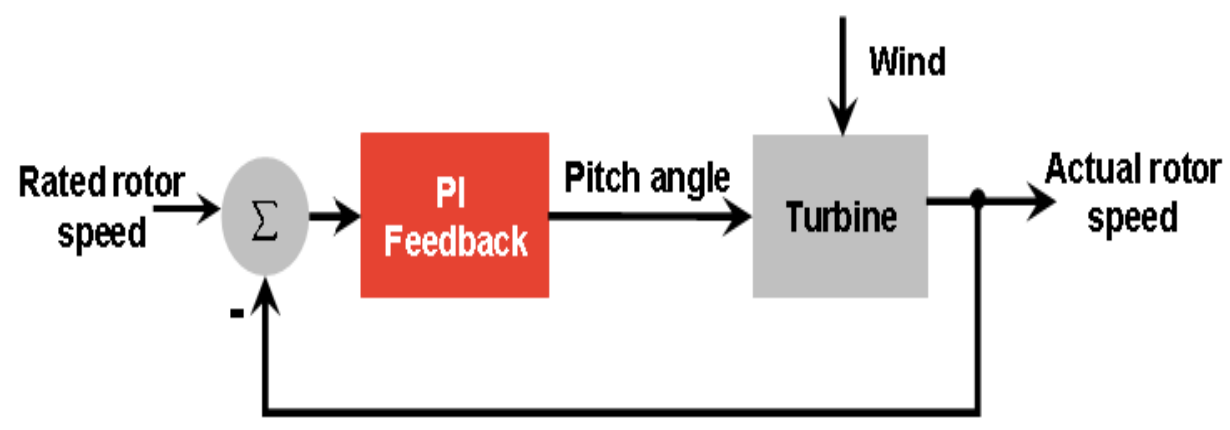

Figure 6. A PI collective blade pitch control configuration in above rate wind speed condition Based on (fig.6), a generator torque control algorithm can be defined by

$$
\tau_{C}=K \Omega^{2}
$$

Where $\mathrm{k}$ is the torque coefficient, which is derived to make $\lambda_{C}=\tau_{\text {aero }}$ aero at the optimal TSR and is given by

$$
K=\frac{1}{2} \rho \pi R_{a}^{5} \frac{c_{p \max }}{\lambda_{*}^{3}}
$$

The torque controller in equation $(6,7)$ is designed to maximize Cp (M. \& I 1992) and and are the optimal TSR and blade pitch angle, respectively, at which the maximum $\mathrm{Cp}(\mathrm{Cpmax}=\mathrm{Cp}()$,$) occurs. Generally, the pitch$ angle is kept constant at, which is also known as the ne pitch angle, below rated wind. The generator torque algorithm (6)-(7) was taken as the baseline torque controller for CART3 in this paper, with a proprietary slight variation for the Alstom ECO-100. Yaw control is used to adjust the wind turbine to be aligned with the wind direction (G. H \& K, P. n.d.). In this paper, yaw is assumed to operate acceptably, and the novel turbine control methods developed are focused on advanced ADTC controllers.

\section{Optimum Design of Wind Turbine System}

Energy is the basis for economic development and it is important to have a reliable supply of energy for the sustainable development of any country. With the rapid growth of the global economy, the energy crisis is aggravating substantially. It is, therefore, of great interest to develop renewable energy systems that can take up a relatively large proportion of the growing energy needs with the crucial features of controlling the detrimental effects to the climate. High efficiency nuclear energy was once regarded as a priority compared to other energy sources. However, (HSBC Global Research 2011) reported that the 2011 Japanese nuclear disaster has seriously reduced the reputation of nuclear energy in terms of energy security. After this nuclear accident, the growth of nuclear energy development is becoming slow and all countries have been seriously re-examining their strategies of energy development. Any energy development has to strictly satisfy the fundamental requirements of human society, such as no pollution, safety and health.

\section{Advantages of Wind Energy}

As pointed in the previous section, finding the desirable alternative energy to meet the increasing demands of energy is of critical importance for the global economic growth and environmental protection. Since the beginning of the twenty first century, countries all over the world and international organizations have invested tremendous amount of funds for the development of such energy resources. A variety of energy sources, 
including traditional hydropower, biomass, solar energy, and wind, have been proposed and studied in terms of solution to the energy crisis. Among them, the solar photovoltaic energy system is found to have a lower energy conversion efficiency and high manufacturing cost and hence the cost-benefit trade off makes solar energy system uneconomical for use on a large scale. In terms of hydroelectric power, the construction of a dam will submerge considerable tracts of land, and also involves a large scale residential migration which results in a huge investment. From International Water Power and Dam Construction, a governmental report indicates that the estimated cost of the largest Three Gorges Dam project would be $\$ 22.5$ billion, which make it the costliest hydroelectric power project. The original source of wind energy is wind due to the presence of atmospheric motion, which results from the temperature difference caused by the uneven heating from the sun. (Wijk et al. 1993) estimated conservatively that the world's available wind resource could be 20,000 TWh/year. In 2008, Sovacool (B.k 2011) studied the greenhouse gas emission and impact of wind energy and concluded that the wind energy emits the least amount of greenhouse gases by comparing with other energy alternatives, as shown in Table 1.

Table 1. Lifecycle greenhouse gas emission estimates for electricity generators (B.k 2011)

\begin{tabular}{|c|c|c|}
\hline Technology & Description & $\begin{array}{l}\text { Estimated greenhouse gas } \\
\left.\text { emission ( } \mathrm{g} \mathrm{CO}_{2} \mathrm{eq} / \mathrm{kWh}\right)\end{array}$ \\
\hline Wind & $2.5 \mathrm{MW}$ offshore & 9 \\
\hline Hydroelectric & 3.1 MW reservoir & 10 \\
\hline Wind & 1.5 MW onshore & 10 \\
\hline Biogas & Anaerobic digestion & 11 \\
\hline Hydroelectric & $300 \mathrm{~kW}$ run-of-river & 13 \\
\hline Solar thermal & $80 \mathrm{MW}$ parabolic trough & 13 \\
\hline Biomass & Various & $14-35$ \\
\hline Solar PV & Polycrystaline silicon & 32 \\
\hline Geothermal & $80 \mathrm{MW}$ hot dry rock & 38 \\
\hline Nuclear & Various reactor types & 66 \\
\hline Natural gas & Various combined cycle turbines & 443 \\
\hline Fuel Cell & Hydrogen from gas reforming & 664 \\
\hline Diesel & Various generator and turbine types & 778 \\
\hline Heavy oil & Various generator and turbine types & 778 \\
\hline Coal & Various generator types with scrubbing & 960 \\
\hline Coal & $\begin{array}{l}\text { Various generator types without } \\
\text { scrubbing }\end{array}$ & 1050 \\
\hline
\end{tabular}

Thus wind energy can be considered as an inexhaustible source of energy as well as a green energy. The rapid developments of manufacturing and power electronics technologies greatly facilitate the use of wind energy. Among the various renewable energy sources, wind energy has a promising prospect for large scale commercialization since the investment in a wind power generation system can be reduced with an increase in its installed capacity, along with the advantages of having an inexhaustible supply of clean and safe wind energy. As a competitor to the conventional energy sources, wind energy is considered to be an important source for a diversified energy portfolio.

\section{Development of Wind Energy}

According to Renewables 2011 Global Status Report(REN21 2011), the net increase of wind power capacity reached 39 gigawatt $(\mathrm{GW})$ in 2010, more than any other type of renewable energies, and the proportion of wind energy in the total global energy capacity rose to more than $24 \%$ relative to 2009 (REN, 2011). The data 
presented in the Renewable Energy Consumption and Electricity Preliminary Statistics 2010 Report, distributed by the U. S. Department of Energy, shows that the proportion of wind energy accounted for the total renewable energy consumption had increased from $4 \%$ to $11 \%$, whose net growth is larger than any other energy resources, while the proportion of biomass taken into the total renewable energy consumption has increased only by $4 \%$, and the proportion of hydroelectric taken into the renewable energy consumption had decreased from $43 \%$ to $31 \%$ and the proportion of geothermal and solar energy stayed steady (Administration 2011) has abundant wind resource, and the wind energy in U.S. has been experiencing a rapid development since 2000. The national data reflects wind energy development trends in the U. S., as shown in Figure .6, 7, and 8.2 respectively The U. S. Department of Energy has estimated that the demand for electric power would increase by $39 \%$ from 2005 to 2030, reaching 5.8 billion MWh by 2030. It is expected that the wind energy share of America's electricity supply can be increased to $20 \%$, known as the $20 \%$ wind scenario (Administration 2011).

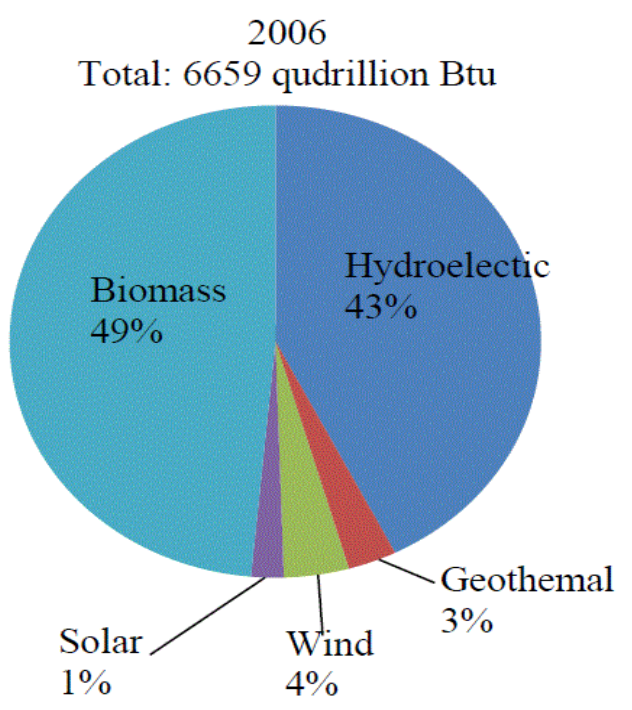

2010

Total: 8049 quadrillion Btu

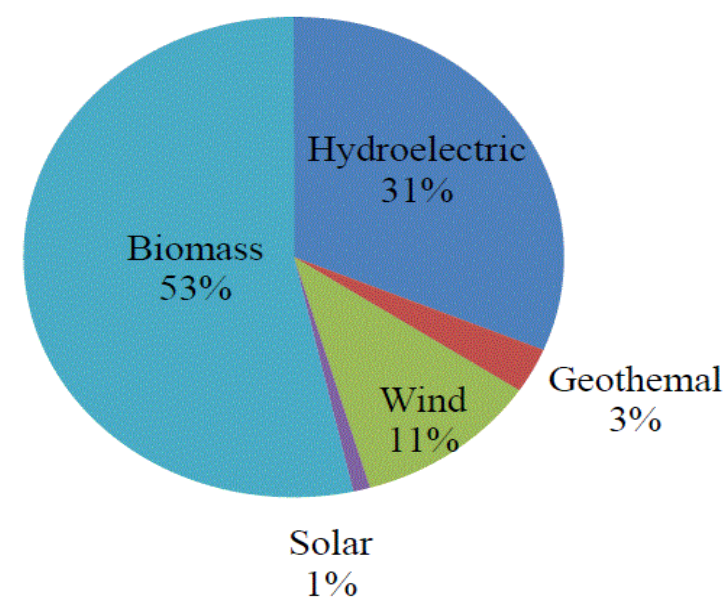

Figure 7. Renewable energy consumption in U. S. (Administration 2011)

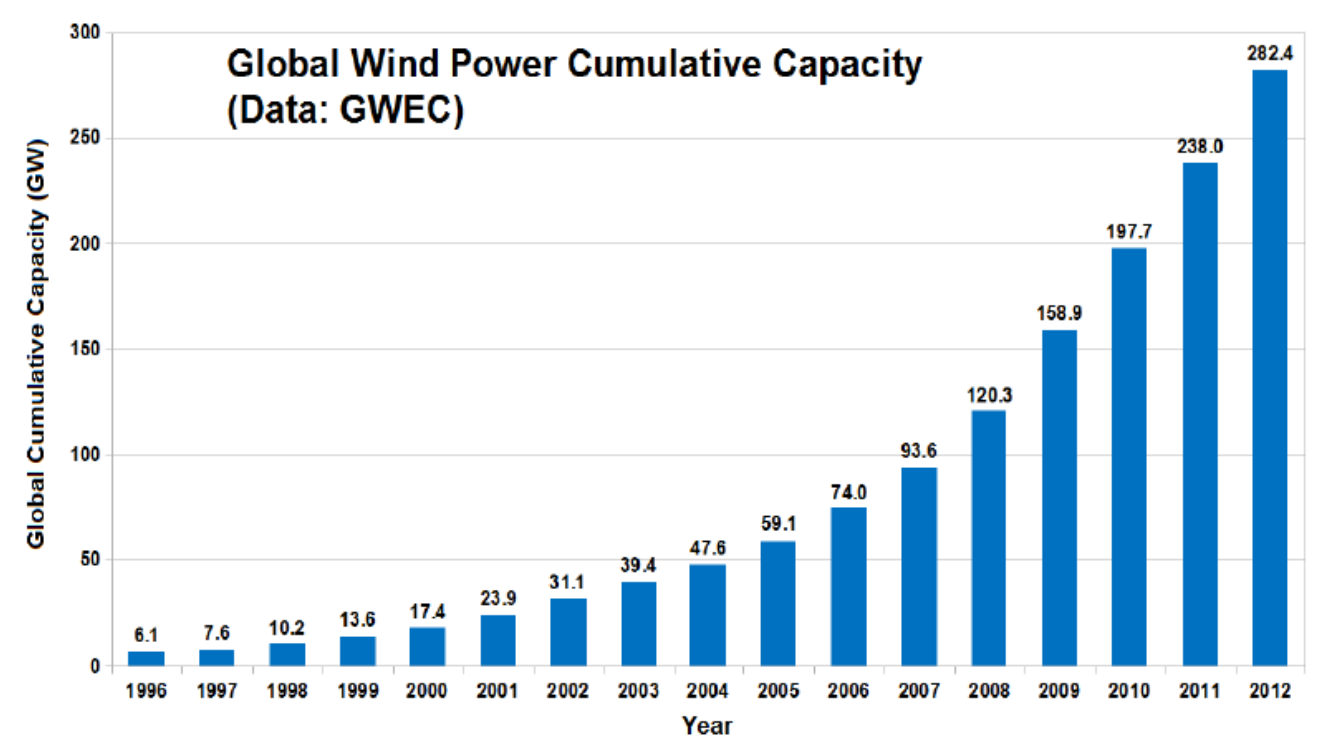

Figure 8. U. S. Wind energy generation by year 2011 (U. S. D. of Energy 2008) 


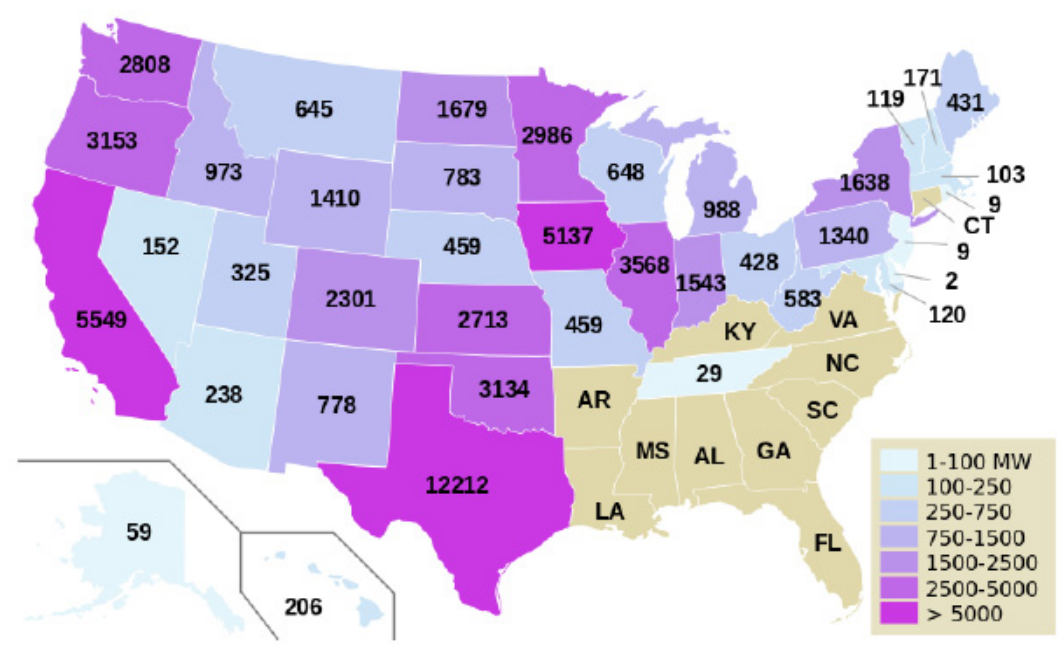

Figure 9. Maps illustrating installed wind power generating capacity for U.S. states at the end of 2011

\section{Description of Wind Turbine Technology}

As a key component of the wind energy system, the wind turbine can be classified into two major types, the vertical axis wind turbine and the horizontal axis wind turbine, according to its structure, as shown in Figure 1-3 (a) and (b). Darrieus invented thevertical axis wind turbine in 1931. The vertical axis wind turbine can extract wind energy from any direction without yaw control. But, the vertical axis wind turbine has relatively low efficiency since it mounts closer to the ground where the wind velocity is not relative high. Hence it has not been used for commercial wind power systems on large scale. The horizontal axis wind turbine is now widely used in the grid-connected wind power generation systems. In this thesis, the horizontal axis wind turbine is selected for use in the power generation system

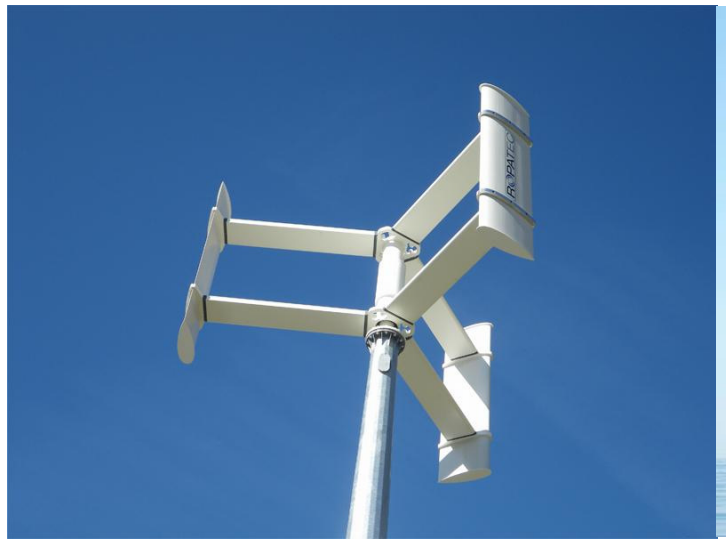

(a)

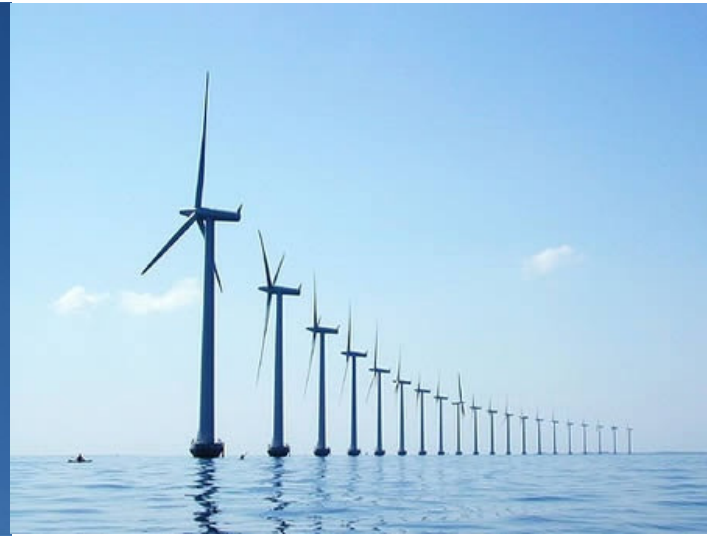

(b)

Figure 10. Vertical axis (a) wind turbine and horizontal axis wind turbine (b) (Administration 2011)

\section{Overview of Wind Turbine System}

Joselin Herbert et al., (2007), Smith et al. (1981) and Molina et al. (2011) presented detailed reviews of wind energy technologies from the view point of overall wind power generation systems. A general wind power generation system is composed of horizontal axis wind turbines with rotors having a set of blades, a transmission gear box and a compatible generator with electronic devices. The structure of a typical horizontal axis wind turbine system is shown in Figure 11: 


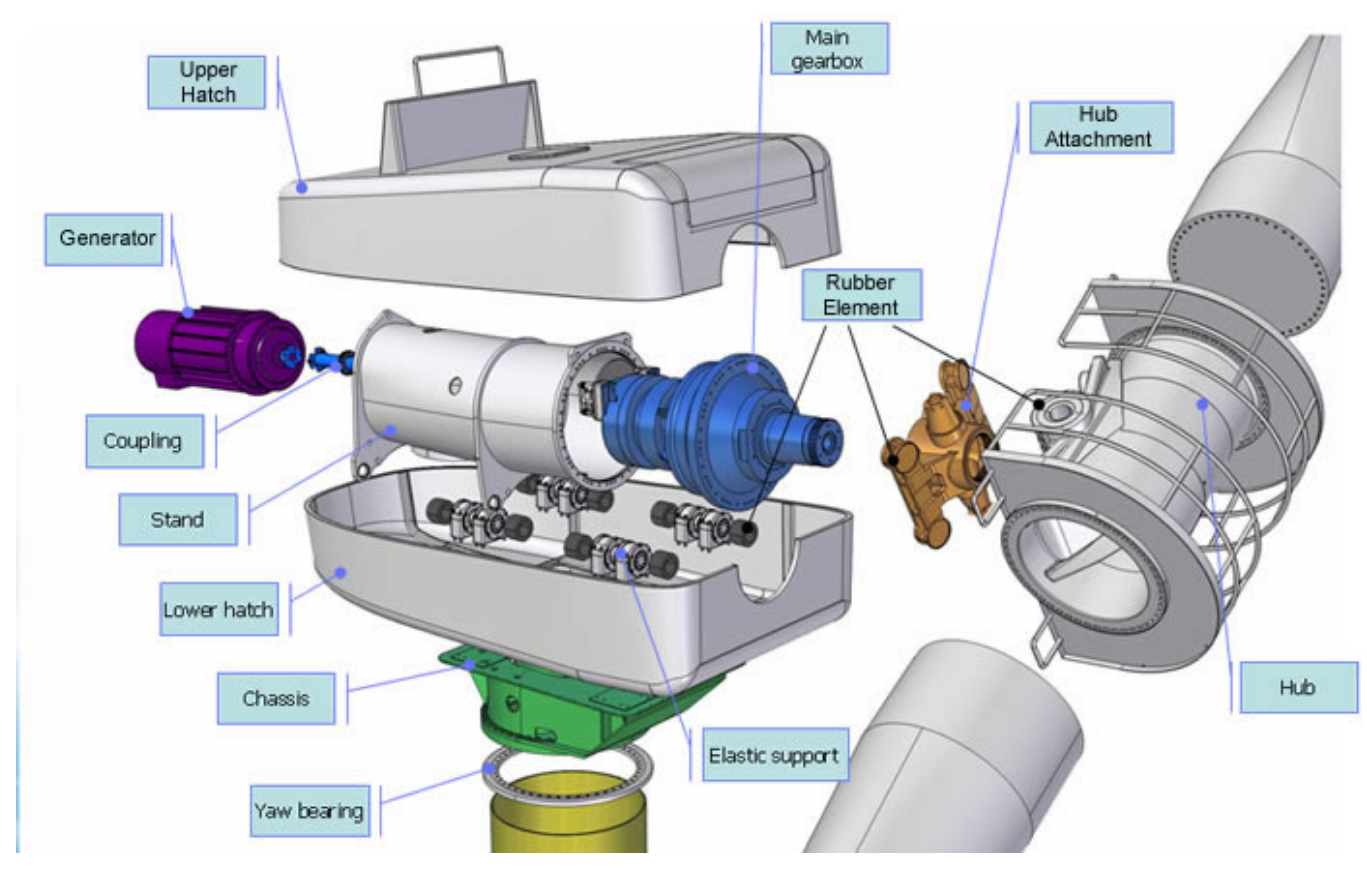

Figure 11. Structures of three-blade type horizontal axis wind turbine system (M.G \& J.M.G 2011)

The output rotational speed of a wind turbine is usually not constant because of wind velocity variations, and the output electricity frequency should meet the constant requirement for connection to the grid $(60 \mathrm{~Hz})$. Thus, a wind turbine can operate in two different schemes - at constant speed and at variable speed - in terms of the speed of the rotor. The various types of generators used in wind power systems are described and compared in detail by $\mathrm{Li}$ and $\mathrm{Chen}$ ( $\mathrm{H}$ et al. 2006). The induction generator is widely used in both the operation schemes, since an induction generator has no synchronization problem along with a higher reliability and manufacturing simplicity. For a constant speed wind turbine system, the generator is connected to the grid directly, and the rotor speed of the generator is decided by the grid frequency. The variable speed wind turbine system allows the variation of the turbine speed and generator speed. Cadirci and Ermis (M. \& I 1992) described, in detail, a variable speed wind turbine power generation system to achieve a maximum total electric power. The type of wind is greatly on the range of the power generated in which that Both HAWTs and VAWTs have their advantages: HAWTs are more commonly used because of their high efficiency in power production while VAWTs are more suitable on sites where the wind direction is highly variable and also they can be easily integrated into buildings. The disadvantages for HAWTs are that they need higher wind speeds to start generating electricity and also become less efficient at producing power in very high winds over $90 \mathrm{MPH}$. They cannot be installed in turbulent wind conditions because they must point into the wind direction to produce power and their blades are structurally less strong as wind speeds increase. Therefore they cannot withstand extreme weather conditions due to frost, freezing rain or heavy snow plus heavy winds in excess of 110MPH. The key disadvantages of VAWTs include the low rotational speed with the consequential higher torque and hence higher cost of the drive train, the inherently lower power coefficient, the 360 degree rotation of the aero foil within the wind flow during each cycle and hence the highly dynamic loading on the blade, the pulsating torque generated by some rotor designs on the drive train, and the difficulty of modeling the wind flow accurately and hence the challenges of analyzing and designing the rotor prior to fabricating a prototype (M.C et al. 2010). In this dissertation, the major focus of design and optimization is HAWT because they are more commonly used. Some study and discussion of VAWT are also included. From all details above, we can tabulate the advantage and disadvantage of common types of wind energy as the following:

\subsection{HAWT and VAWT Wind Turbine Feature's}

The following disadvantages caused the VAWT to have a diminished presence in the commercial market:

1) Reduced aerodynamic efficiency: much of the blade surface is close to the axis.

2) Housing usually at ground level so it is not feasible to have the gearbox of large VAWT at ground level 
because of the weight and cost of the transmission shaft. In HAWT, the wind turbine blades rotate about an axis parallel to the ground and wind flow. Almost all the larger turbines employed in modern wind farms are HAWT because they are more suitable for harnessing more wind energy. However, HAWT are subjected to reversing gravitational loads (structural load is reversed when the blade goes from upwards to downwards position) which impose a limit on the size of such turbines (M.C et al. 2010) .he rotation of both HAWT and VAWT can be powered primarily by lift or drag force depending on the design of the blade.

\subsection{Variable-Speed Pitch-Regulated Wind Turbine}

A variable speed wind turbine can incorporate a pitch regulation feature that involves turning the blades about their lengthwise axes (pitching the blades) to regulate the power extracted by the rotor.

\section{Advantages:}

1) Turbine can operate at ideal tip-speed ratios over a larger range of wind speeds so as to capture maximum energy from wind.

2) Ability to supply power at a constant voltage and frequency while the rotor speed varies.

3) Control of the active and reactive power.

\section{Disadvantages:}

1) Generates variable frequency current/voltage so needs power electronic converter.

\subsection{Fixed-Speed Stall-Regulated Wind Turbine.}

When the wind speed increases, the blades become increasingly stalled to limit power to acceptable levels without any additional active control hence the rotor speed is held essentially constant.

\section{Advantage:}

1) Simple and robust construction, hence lower capital cost.

\section{Disadvantages:}

1) Cannot extract optimum energy from wind.

2) Do not have the capability of independent control of active and reactive power.

3) Generates more mechanical stress on gearbox during variable wind speed.

The modern wind turbine industry is shifting towards variable speed because of their better overall performance. They take full advantage of variations in the wind speed; encounter lower mechanical stress and less power fluctuations and provide $10-15 \%$ higher energy output compared with constant speed operation (Anca D. \& Lov 2009). The number of blades used in wind turbine also affects its performance. To extract maximum possible amount of wind energy from wind, the blades should interact as much as possible with the wind blowing within swept area. Theoretically, more the number of blades a wind turbine has, the more efficient it should be. But in reality, when the number of blades increases; there will be more interference within blades. As a result, it is more likely that blade will pass through the disturbed weaker windflaw region. From a structural stability viewpoint, the number of blades of HAWT should be odd and greater or equal to 3 , in which case the dynamic properties of the turbine rotor are similar to those of a disc (Muljadi et al. 2000). Hence most of the commercially available modern wind turbines are three-bladed. Betz law says that we can only convert less than $16 / 27$ (or 59.3\%) of the kinetic energy in the wind to mechanical energy using a wind turbine (Muljadi et al. 2000). It is because the wind after passing through wind turbine still has some velocity. Within the turbine, most of the energy is converted into useful electrical energy, while some of it is lost in gearbox, bearings, generator, power converter, transmission and others (Muljadi et al. 2000). Most practical rotors with three blades can reach an overall efficiency of about $50 \%$.

\section{Literature Review of Design of Wind Turbine System}

The wind power technology is a multidisciplinary technology involving meteorology, aerodynamics, mechanics, electronics and control. Many research works conducted on the horizontal axis wind turbine power generation systems contributed considerably to the development of high capacity wind turbine systems. Vries (De \& Vries 1983) presented a review of the basic aerodynamic conversion process of a horizontal axis wind turbine by considering both single and multiple stream analyses. Sorensen (Sorensen \& N 2001) presented a review paper on the theoretical, computational and experimental scopes of the aerodynamics of wind turbine. From these reviews, it is seen that the major methods for the aerodynamic modeling of a horizontal axis wind turbine include 
blade element momentum theory, Navier-Stokes computational fluid dynamics simulation of wind turbines and Lagrangian particle vortex methods (G. H \& K, P. n.d.) etc. Although the computational fluid dynamics method permits consideration of rotor wake influence, other meshing problems may arise when the blade keeps rotating and deforming as well as the difficulty associated in separating the rotor boundary layer. The Lagrangian particle vortex method is also a computationally intensive and time consuming method (C n.d.)The blade element momentum theory is effective in accounting for the aerodynamics of horizontal axis wind turbines, and has been used widely for aerodynamic modeling. The axial momentum theory was initially proposed by Froudes to analyze the behavior of a wind turbine rotor, which is based on the study of the extraction of kinetic energy when wind flow passes through a rotor disc by assuming the flow to be incompressible and homogeneous (S 2006). Glauert (G \& R 1985) developed the blade element momentum theory as an analytical method for estimating the aerodynamic performance of horizontal axis wind turbines, and also introduced the Prandtl tip-loss approximation into the blade element theory (L 1919). Wilson, Lissaman, and Walker (1976) made an important contribution to the aerodynamics of wind turbines by combining axial momentum theory and blade element theory. (A et al. 2007)presented a methodology in developing an aerodynamic model of a horizontal axis wind turbine with consideration of main rotor and wake by using tunnel test data through interpolation Maheri, Noroozi and Vinney (S.M \& I.A 2000)pointed out the difficulty associated with the use commercial codes for the analysis of the coupled aero-structure wind turbine problem due to the iterative process involved in finding the axial induction factor, and described a procedure for the simulation of wind turbines by considering the twist distribution along the blades. Habali and Saleh (S.M \& I.A 2000) conducted analytical and experimental studies for the evaluation of the design of wind turbine blades, and demonstrated the measured power characteristics of the wind turbines designed. Bonnet, and Dutton (P. A \& G 2007) described a procedure for the flexible parametric modeling of a wind turbine rotor and discussed the behavior of large wind turbines. The aspect of wind turbine system optimization has been explored extensively in the literature. Burton (G \& R 1985) found that the maximum power coefficient of a horizontal axis wind turbine is $16 / 27$, which became known as the Betz limit. The optimal design of wind turbine systems involves many aspects, such as output power generated, manufacturing cost, and strength. Several researchers conducted the optimization of wind turbine systems with different objectives. Lanzafam and Messina (R \& M 2009) conducted geometric parameter optimization for a two-bladed horizontal axis wind turbine system to maximize the annual energy production by finding the optimum twist angles alone. Maalaawi (K. Y \& M 2002) proposed a direct method for the optimization of horizontal axis wind turbines by formulating an approximate cubic polynomial function of the axial induction factor to find the optimum chord and twist distributions. Amano and Malloy (R. S \& R. J 2009) proposed a computational fluid dynamics method for the optimization of a wind turbine rotor. Liu, Chen and Ye (2007(R. S \& R. J 2009) developed a procedure for the optimization of wind turbine blades based on an extended genetic algorithm. The maximization of the average power generated by the wind turbine was considered as the objective function based on an assumed probability distribution of wind velocity. The chord and twist distributions of the blades are treated as design variables. They used Bezier curves to constrain the geometric design parameters; however, the behavior constraints associated with the wind turbines were not considered. It is noted that constraints on the wind turbine behavior have not been considered in the optimization works indicated above. Some research investigations have included constraints in the optimization of wind turbine systems. Negm and Maalawi (K. Y \& M 2002) presented a general method for the optimization of wind turbine towers with mass and deflection constraints. Karam and Negm (H.M \& K.Y 2000) presented a method for the frequency optimization of wind turbine blades with behavior constraints on the axial induction factor and tip deflection; however the power capacity of the wind turbine has not been included in the optimization process. Fuglsang and Madsen (P \& H.A 1999) reported a structural optimization procedure for minimizing the cost of energy with a constraint on approximate blade fatigue, and the optimal rotor chord and twist distributions are found by applying sequential linear programming and the method of feasible directions. Benini (E \& A 2002)applied genetic algorithm for the optimal blade design of a horizontal axis wind turbine. The optimization aims to finding the values of the blade parameter along the span direction. The objective function was considered as a combination of the average annual power coefficient and the average energy production cost. They included the stresses induced on the rotor hub as nonlinear behavior constraints.

\section{Introductory Remarks of Doubly Fed Induction Generator System}

The power conversion from mechanical power captured by the turbine rotor to electrical power is performed by a generator. It must be noted that electrical power output from the generator cannot preserve constant values of voltage and frequency because of the stochastic characteristic (nature) of wind velocity. 


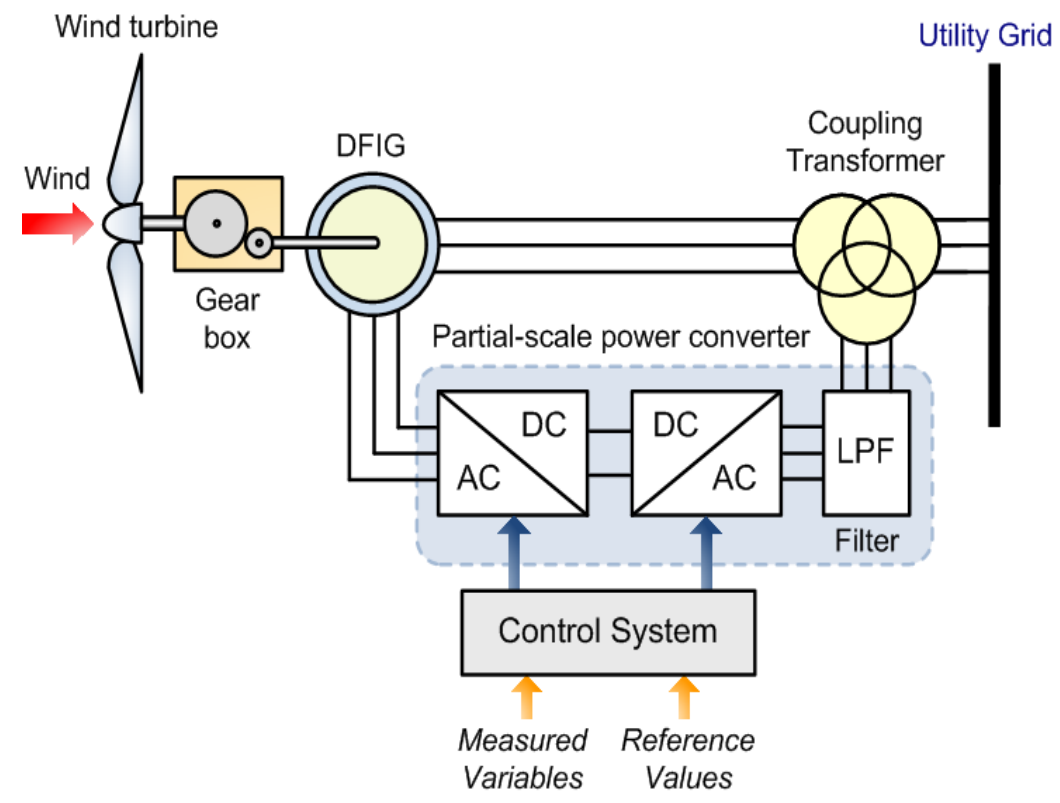

Figure 12. Variable Speed wind turbine with doubly fed induction generator system (M.G \& J.M.G 2011)

From the aspect of the grid, the electrical power must be stable for grid consumers from the point of view of magnitude and frequency of electrical quantities. Thus, a frequency converter, like power electronic converters, is applied to adjust the electrical output to the desired values of voltage and frequency. Many efforts have been made to study the behavior of wind power generator systems. Chen, Guerrero ( $Z$ et al. 2009) presented a detailed review of the power electronics systems used for wind turbines. The converters that have been applied to the doubly fed induction systems are described and discussed in detail by Baroudi (N, S. et al. 2005). A general frequency converter for wind generator includes a rotor-side converter, a grid-side converter, a filter and their control modules. The electrical power used for excitation is transformed from the AC circuit to the DC circuit by a rectifier, and the DC circuit, controlled by an inverter, is converted into a regulated AC circuit with desired values of voltage and frequency. The capability of modulating the magnitude and frequency of the excitation current enables the system to yield more electrical energy with a variable wind speed.

\section{Uncertain Analysis in Design and Analysis}

It is noted that most research works in engineering design and analysis have been conducted using deterministic quantities. With an in-depth observation of the presence of uncertainty in most parameters, engineers realize that an effective treatment of uncertainty is required for the understanding the nature and behavior of objects, and the methods of deterministic analysis and design cannot yield accurate and good results. At present, there is a growing interest in uncertainty analysis and design among investigators from various disciplines. Ayyub (M, Bilal 1997) presented a general description of modeling methods for uncertainty analysis from the view point of reliability assessment in structural and environmental systems. Cacuci (Cacuci \& Cacuci 2004) conducted analytical and computational studies for a comparison of results given by the sensitivity and uncertainty analyses. Beck (M. B 1987) studied the effects of uncertain parameters and uncertain relationships among variables on the modeling of water quality and also provided a detailed review of the evaluation of different methods of uncertainty analysis. Isukapalli (S. S 1999) proposed a stochastic response surface method for uncertain analysis in transport transformation models. Marino ( $\mathrm{S}$ et al. 2008) presented methods of uncertainty and sensitivity analyses as applied to biological dynamic models. The methods used for the uncertainty analysis depend on the nature of the uncertainty. The uncertainty analysis can be characterized as stochastic analysis, fuzzy analysis and interval analysis. The uncertain variables are described as random variables (numbers) in the stochastic analysis and the stochastic analysis uses the ideas of probability theory as the mathematic approach. The uncertain variables are described as fuzzy numbers in the presence of vague, imprecise of fuzzy information. The analysis in the presence of fuzzy information is conducted by defining membership functions for the fuzzy parameters. In the interval analysis, each of the uncertain parameter is assumed to vary between two values (i.e., in an interval). The analysis, in the presence of interval quantities, is conducted using interval arithmetic operations. 


\subsection{Overview of Stochastic Method}

In this method, the uncertain quantities are described as random variables characterized by their mean values and standard deviations. The uncertain system is then converted into a probabilistic model, and the probability of outcome response of the uncertain system can be found by using probability theory (N.U 2007) (M \& M 1995). The stochastic modeling and analysis is one of the important research topics in mathematics and engineering. Kall and (P \& S.W 1994) and Prade described and discussed the theoretical and computational aspects of the probabilistic approach used in stochastic analysis problems. Hald (A 1952) presented a detailed review of the applications of statistical methodology in different types of engineering problems. Michel (K.O 1990) described a procedure for the stochastic analysis of various engineering problems.

\subsection{Overview of Fuzzy and Interval Methods}

In classical mathematical concepts and set theory, an object is considered either belongs to a specified set or does not belong to the set, $a \in U$ or $a \notin U$. This concept is generally used for crisp or distinct numbers. In most real life situations, often it is not possible to describe the problem in precise mathematical form in terms of crisp quantities. Descriptions, such as "the room temperature is not comfortable", "the fiber content of the fiber-reinforced composite plate is low", and "the forcing frequency is too close to the natural frequency", cannot be expressed in crisp mathematical forms. Fuzzy set theory can effectively modeled such domains in which the descriptions and observations are "fuzzy", in the sense that there are no sharply defined boundaries of the set of activities or observations to which the descriptions apply. Since the fuzzy set theory is concerned with linguistic statement of degree of support for membership in imprecise sets, a degree of membership is used to describe a fuzzy quantity. Fuzzy set theory was initiated by Zadeh (L.A 1965). The nature of fuzzy number indicates the essential property of uncertainty within the transitional boundary of information or systems. Although the application of fuzzy theory was limited to the academic study alone at the beginning, the fuzzy theory has been widely used in the following few years for the uncertain analysis of a variety of engineering problems, such as those related to pattern recognition, artificial intelligence, controls, decision making, and optimization. The fuzzy theory and fuzzy arithmetic are found to be useful tools for the quantification of imprecision present in most practical systems. Rao (S.S \& L.T 2001) developed a fuzzy finite element method for the analysis of uncertain systems. The imprecise information present in the geometry, material properties, external loads, and boundary conditions is modeled using fuzzy numbers with well-defined membership functions. The fuzzy calculus and fuzzy integration techniques are used to derive the fuzzy system stiffness matrix and fuzzy load vector. An unconstrained minimization method is introduced to solve the fuzzy system equations. Rao and Cao (S.S \& L.T 2001) developed a fuzzy boundary element method for the analysis of imprecisely defined heat transfer problems. The boundary element analysis using the fuzzy $\alpha$-cut approach is conducted by treating both the specified boundary temperatures and nodal coordinates as fuzzy parameters. Six discrete values of $\alpha$ are used in the numerical computation. The fuzzy responses are found by solving the linear system of fuzzy equations using a modified Gaussian elimination method, coupled with a truncation scheme. Dubois and Prade (D \& H 1985)and Bortolan (G \& R 1985) presented detailed reviews of fuzzy algorithms developed for the solution of fuzzy equations. Zimmermann (H.J 2011) presented the arithmetical aspects of fuzzy numbers. Tong (R.M 1977) described and discussed fuzzy algorithms in the context of control programming. Moller, Graf and Beer (B \& W 2000) presented a modified structural optimization algorithm based on the combination of fuzzy $\alpha$-level analysis and deterministic optimization. In many practical cases, the ranges of the uncertain parameters are readily available. But the information on the probability distribution or linguistic information on the uncertain variables may not be readily available in many cases. In the interval analysis, all the system parameters are treated as interval numbers as $A=[A-\Delta A, A+\Delta A]$ with $A$ denoting the nominal value and $\Delta A$ the deviation from the mean on either side. This involves the application of interval arithmetic to every step of calculations. Since it is not always possible to find detailed information on the uncertainty of a parameters, an interval statement on the uncertainty of a parameter, an interval statement can be conveniently used as a general indication of the imprecision that exists in an engineering problem. This means that we need not know the probability distribution of the random variables or the fuzzy subsets of the uncertain variables. In addition, in fuzzy analysis, each fuzzy quantity or parameter is described by a membership function, $(x)$, which is required to be convex and normal. The function ( $x$ ) denotes the grade of membership of element $x$ in the fuzzy set $A$. If $(x)=1$ for some value of $x$, then this value is definitely a member of the fuzzy set $A$. Similarly, $(x)=0$ implies that the particular $x$ is definitely does not belong to the fuzzy set $A$. Any value of $x$ in the range 0 to 1 indicates that the membership of $x$ in $A$ is vaguely defined. For computational purpose, the range of membership function, 0 to 1 , is divided into a finite number of discrete values, known as $\alpha$-cuts. For each $\alpha$-cut, the range of the fuzzy quantity can be treated as an "interval" of the fuzzy quantities. Thus "interval analysis" can be used for fuzzy analysis using $\alpha$-cuts. In 
practical computations, in order to introduce input fuzzy numbers into the analysis, the membership functions of the fuzzy numbers are deliberately discretized with respect to a set value of $\alpha$-cut. The interval at each value of $\alpha$-cut represents the range of response corresponding the $\alpha$-cuts. Thus, $\alpha$-cut approach enables fuzzy analysis using interval analysis at each $\alpha$-cut. Hansen and Walster (R.E \& P.B 1976) discussed, in detail, methods of interval optimization based on the use of interval numbers and arithmetic. Inuiguchi (M \& M 1995) presented the basic principles and procedures for linear programming problems with considerations of an interval objective. $\mathrm{Wu}$ and Rao (W.D \& S.S 2004) presented an interval analysis method to investigate the modeling of geometrical dimensions and their tolerances. The interval analysis is used to find the optimal allocation of mechanical tolerances of different mechanisms such as the four-bar mechanism, the clutch assembly, and Stanford manipulator. Majumder and Rao (L \& S.S 2009) demonstrated the idea of interval optimization as an alternative to probabilistic method to solve uncertain problem dealing with multiobjective optimum design of aircraft wings under gust loads. In their work, the input system parameters were described as fuzzy variables and the fuzzy responses of the system at each $\alpha$-cut level were found using the fuzzy set theory and interval arithmetic. The multi-objective optimization, including minimization of weight, minimization of energy needed and maximization of flutter Mach number of aircraft wing structures, was conducted at a series of $\alpha$-cut levels.

\section{The Main Design Challenges of the Wind Turbine Control}

An inspection of literature view on advanced control strategies for WTs points out the following as the leading design challenges:

1. Wind disturbances disturb the performance of the closed loop system.

2. Unmodeled dynamics influence the stability and performance of the closed-loop system.

3. The main source of the nonlinearity in W.Ts, i.e. the function, is unknown, and changes through the course of operation of a W.T.

4. W.T dynamics indicate wind-dependent behavior, which means that the parameters of a

WT model are different at different wind speed operating points.

5. Wind speed estimation or light detection and ranging (LIDAR) measurements of wind

Speed may have mistakenness.

6. Faults may occur in the components of the wind energy transformation system (WECS).

In next pages we will talk about the strategies adopted in the literature to address some of these challenges are briefly pointed out.

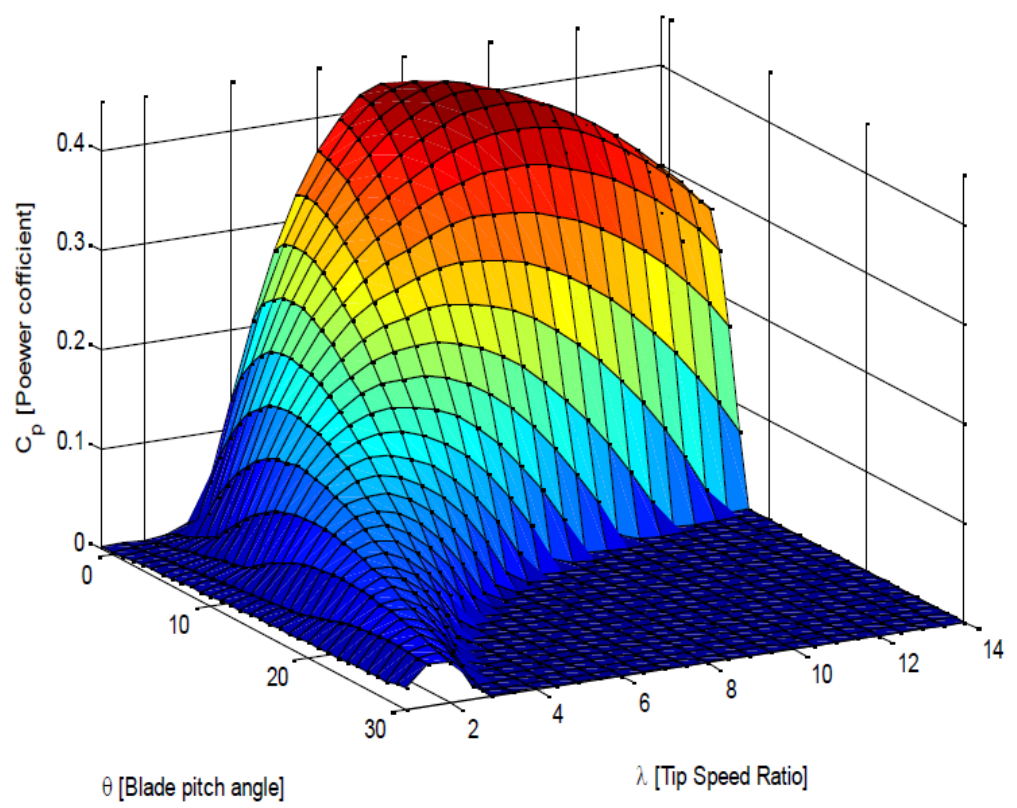

Figure 13. CART's $\mathrm{Cp}$ surface as a function of pitch angle and tip speed ratio ( $\mathrm{K}$ et al. 2006) 


\subsection{Nonlinear Feedback Control}

As shown in Fig 2. 12 the surface is a nonlinear function of the pitch angle and the tip speed ratio (or rotor speed and wind speed). As a result, aerodynamic torques and bending moments are nonlinear functions of wind speed, pitch angle and rotor speed (L \& K 2009). This would normally show that specific reference tracking in WECS can be improved reached through nonlinear control methodologies. This issue has been talked in the literature. For example, a feedback linearization control strategy was introduced in (S \& N 2007) to handle the problem of nonlinearity in WTs and to detach the wind disturbance from the dynamics of the turbine. The authors used the same model for both Controller design and simulation, and reported promising results.WTs are sophisticated systems with many subsystems, supplemented parts and coupled modes as in Fig. 12 where not all of these modes are taken into account in the design process of the controller. Nevertheless, these unmodeled dynamics may harmfully affect the stability and performance of the overall closed-loop system. For example, a comparable feedback linearization method as in (S \& N 2007) was adopted in (A \& K 2010) to control the CART coded with FAST; however, it headed to different results. These divergences between the results can be because of assumption of a simplified WT model for controller design purposes, which can additional emphasize the effect of unmodeled dynamics as one of the controller design tasks.

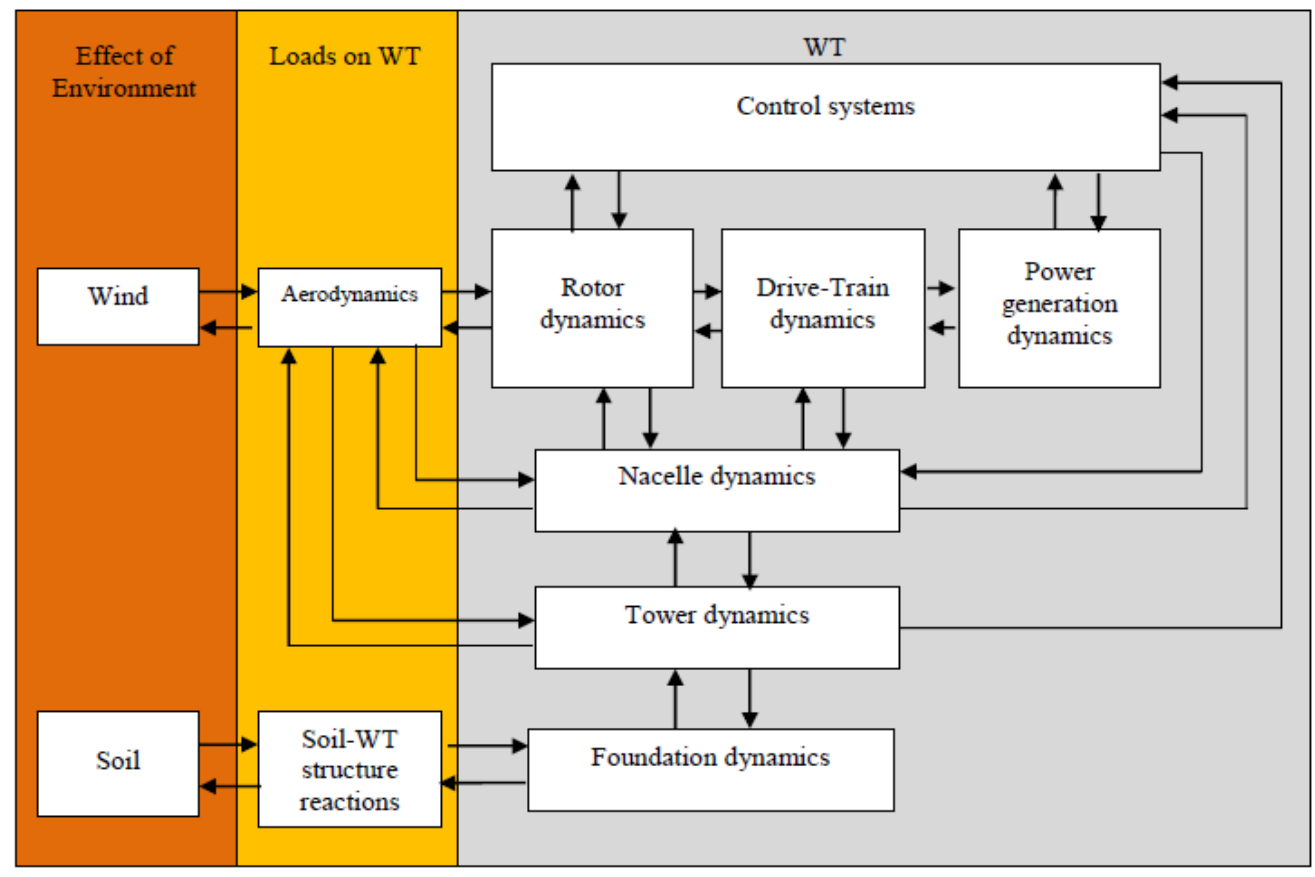

Figure 12. Interconnection of subsystems in a WT and the effects of the environment (J 2007)

Another source of wrongness in the design of feedback linearization based controllers arises from the assumption of having an analytical function for. Even if it is common in the literature to adopt a known surface and accordingly design nonlinear or lookup-table-based policies for control of WTs [(Dodson \& Busawon 2005), this function is in general unknown and additionally, it changes over time for an installed WT (B \& Ali 2008). This means that control systems designed created on the assumption of known $\mathrm{Cp}$ may not be dependable for the purpose of long-term operation; although, more effective controllers may be able to solve this issue to some extent. For example, in (B \& Ali 2008), gliding mode nonlinear control strategy was assumed as a substitute for feedback linearization technique. This controller is inherently robust with high opinion to either nonlinearity in the behavior of the system or the influence of disturbances. However, the talking in the controlled output may put some limitations on pitch actuators and therefore question the achievability of such controllers for control of WTs at region 3. By growing the complexity of the original design, the authors of (Beltran \& Ahmed 2009) introduced a higher order sliding mode controller collective with a sliding mode observer was implemented to solve the chattering problem for generator torque control of WTs (Boukhezzar et al. 2010). In another case, a unusual nonlinear control method has been developed in (Boukhezzar \& Siguerdidjane 2005) to control both speed and power of the generator in a flowed configuration. Also, in order to increase the captured energy and decrease the mechanical load, Kalman filtering was used in (B \& H 2005) in combination with a nonlinear 
dynamics state feedback controller. Regardless of the results, as also noted in (Boukhezzar et al. 2010)-(M \& J 2008), using a nonlinear controller may lead to instability or limit cycle issues as well as the lack of realizable analytical solutions. Hence, while WT has a nonlinear performance and it is shown through simulations that nonlinear control methods improve the performance of WECSs, in the field, linear controllers tend to be more common within the wind industry.

\subsection{PID and Optimal Feedback Control}

It is easy to show that a proportional integral derivative (PID) controller is forceful with respect to constant disturbances. Therefore, under the assumption of having piecewise constant wind disturbances, PID has been widely used to control WTs. PID-based control of WT is discussed in detail in (M 1999). However, since the linearized WT model hinge on the wind speed parameter, even in the absence of any unmodeled dynamics, the parameters of a WT model would differ from one wind speed operating point to another. This means that a PID would not be able to provide any guarantees for general stability of the linear WECS. So as to solve this problem, gain-scheduled PID has been castoff to control the WT (M. et al. 2005)-(A \& L 2008). The start point is to design different PIDs at different wind speed linearization points and find a preparation function based on interpolation of the controllers in order to correct the loop gain appropriately. In this technique, pitch angle and wind speed can be supposed as the scheduling parameters. While this controller shows developed performance in comparison to the traditional approach; similar to the PID method, the design would be sensitive to the unmodeled dynamics. Other control techniques have also been projected in the literature. For example, authors in (B et al. 2007) apply a unique multivariable controller to control CART with the objective of realizing reasonable power regulation while overlooking modeling uncertainties. In other cases, investigators have used multivariable control theory in order to satisfy multiple objectives at the same time. Authors in [24] simulated an optimal control for WTs without making an allowance for modeling uncertainties. Authors of (A \& L 2008)and (K 2003)-(B et al. 2007) used the theories of disturbance tracking control (DTC), disturbance accommodating control and disturbance utilization control in state space with the aim of solve the multi-objective control problem of WTs. Since they expected the wind speed, these methods were efficient in reducing the effect of wind disturbances; however, Wind-dependent behavior of WTs was not measured in their analysis. The impression of DTC was boosted in (K \& M 2003) with the aim of address the periodic behavior of WT dynamics. Nevertheless, this would quiet be ineffective with regards to the unmodeled dynamics of the WT. With the purpose of achieving to a better closed-loop performance, a higher-order model of WT is required that certainly increases the complexity of the design formula. Moreover, in this case, the need for observability would force the designer to utilize additional sensors which would in line add to the price tag of the controller.

\subsection{Robust Feedback Control}

As pointed out in (A 2004) for CART, unmodeled dynamics may lead to poor performance and instability of the WECS. To address this and in order to be able to control plants with modeling uncertainties, passive robust control methods have been adopted (H et al. 2009)-(M et al. 2011). Geng and Yang (H \& G 2010) introduced a nominal inverse-model based controller augmented by a robust compensator to mitigate the effects of nonlinearities and the disturbances. Using this approach, they achieved a robust tracking of the power command. Quantitative feedback theory (QFT) is another robust control methodology in frequency domain which uses feedback values in order to either reduce the effect of modeling uncertainties or satisfy the desired performance of the closed-loop system. This idea was applied to control of WT in (Sanz M \& J 2008). Nevertheless, these solutions do not consider the wind-dependent dynamics of the turbine. To make matters worse, conventional robust controllers lead to very conservative designs for WTs, especially if all aforementioned design challenges are taken into account. Linear parameter varying (LPV) control is another scheme which has been used in the literature to maximize the energy captured, address the unmodeled dynamics of WTs, and consider its wind-dependent behavior (F \& R 2004)-(A. F et al. 2012). This method addresses all aforementioned challenges in linear control of WTs while assuming a measured or estimated wind speed as an independent parameter. In another instance, the author of (M 2004) developed a switching-QFT robust controller to enhance the QFT controller proposed in (Sanz M \& J 2008). Also, authors in (M et al. 2010) designed a multiple-model controller (MMC) for distinct wind speed linearization points to consider the wind-dependent behavior of WTs. However, this approach is not robust with respect to the unmodeled dynamics, and the overall performance is sensitive to the accuracy of wind speed estimation. Additionally, this does not provide any guarantees for transients from one wind speed operating point to another.

\subsection{Adaptive Feedback Control}

Adaptive control could partially solve or entirely the problem of wind-dependent behavior of WTs. This method 
has been evaluated in ( $\mathrm{R}$ et al. 2004) ( $\mathrm{S}$ et al. 2009) and ( $\mathrm{S}$ et al. 2011)-(M et al. 2013). Authors of (T et al. 2006) applied a self-tuning regulator as a step towards adaptive control of WT. A generalized model predictive control was used in (T et al. 2006) as another adaptive approach for pitch control of WTs. A multi-input multi-output self-tuning regulator was simulated in (E et al. 2007) to regulate the output power, and also to decrease the load on WT. Authors of (Johnson et al. n.d.)-(K et al. 2006) argued that the uncertaint $\mathrm{y}$ in the aerodynamic parameters of a WT may lead to non-optimality in tracking of maximum power points of WT. To address this, they used adaptive control ideas to find optimal solutions that could overcome the lack of knowledge about aerodynamic properties of WTs. All these methods showed improvements; however, in general, they do not provide guarantees for stability and performance with respect to unmodeled dynamics. In (S et al. 2009), direct adaptive control strategy of (R \& M 2000) was modified to regulate the generator speed of CART at its rated value while considering wind speed disturbance. In addition to the modeling uncertainty, the main difficulty of this method lies in its assumption on having a strictly positive real system which may restrict its applicability (P \& J 1996). However, this problem is solvable for single-input single-output model of WT. In (S et al. 2011), the method of (S et al. 2009) was improved to separate the non-strictly positive modes from other modes in order to overcome the previous problem and consider the structural modes of WTs. Also, adaptive DTC was developed in (M \& Q 2010) to relax the assumption of having a WT with known parameter values, and was applied for torque control of CART. In ( $\mathrm{M}$ et al. 2013), an adaptive partial state feedback DTC augmented with wind speed estimator was developed and applied to NREL's 5MW WT. Due to the complexity in the design of adaptive controllers for turbulent wind profiles, the simulations were limited to a step-like wind speed profile. Nevertheless, these methods are still not considered robust with respect to modeling uncertainties. To simultaneously address the unmodeled dynamics uncertainty, wind-dependent behavior of WTs, and wind disturbance input in the linear control of WTs, the authors of (V \& F 2013) modified the conventional feedback robust model reference adaptive control idea of (P \& J 1996) and developed a robust adaptive feedback-feed forward pitch controller for CART. Here, the feed forward term was based on adaptive estimation of the changes in wind speed, and the method was verified for both step-like and turbulent wind profiles.

\subsection{Feed forward Control}

As an alternative approach for estimation of wind speed, Fig. 13. Shows how the LIDAR sensor provides information about the wind speed at a distance in front of the turbine (N 2013)-(K et al. 2010).

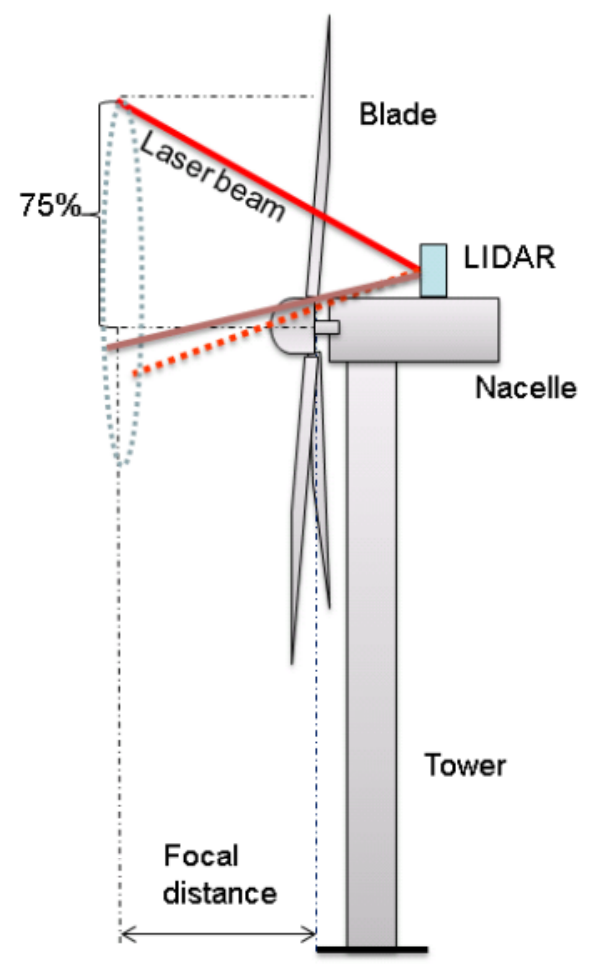

Figure 13. Nacelle mounted LIDAR configuration, adopted from (N 2013) with permission 
In many references, researchers have used LIDAR information for control of WTs, where a trade-off is made between the reference tracking (or regulation) and mechanical load minimization in order to achieve to their control objectives (D. F et al. 2012)-(F et al. 2010). The ideas are very similar to each other and follow the feed forward control theories. These strategies are referred to here as direct LIDAR-based control of WTs. This configuration allows for redesigning the original feedback part with the goal of reducing the required actuation signals (A et al. 2013). In another work, (J et al. 2011) used a LIDAR-based model predictive control loop in addition to the preview feedback controller in order to improve some of the performance indices in control of WTs. However, LIDAR measurement inaccuracies together with the effect of unmodeled dynamics and disturbances in the measurement path can magnify the effect of modeling uncertainties in the feedback loop and may lead to instability of the WECS.

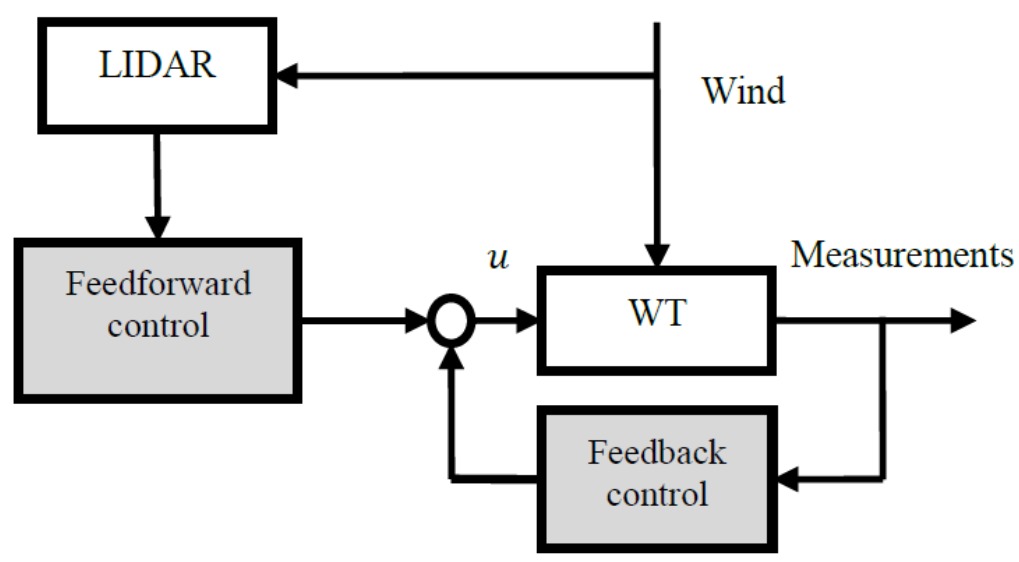

Figure 14. Direct LIDAR-based control of WTs

The authors of (E \& L 2013) used optimal filtering approach to reduce the effect of measurement errors on direct LIDAR-based control schemes. They showed that LIDAR measurement errors in the conventional feed forward strategy could degrade the performance of the closed-loop system. However, they did not consider the unmodeled dynamics or the wind-dependent behavior of the WT model.

\subsection{Fault Tolerant Control}

Regardless of the efficiency of the control ideas discussed earlier, WECSs need different sets of sensors and actuators in order to implement the control schemes. These components are subject to different abnormalities and faults. It is therefore important to investigate the effects of actuator and sensor malfunctions on the general behavior of the closed-loop system (e.g., on power tracking error), and design a controller that enables the WECS to operate successfully in the presence of these unwanted situations. Fault tolerant control (FTC) is a well-researched topic in the control systems literature and is suitable to compensate for these abnormalities (M et al. 2006)-(H \& D 2009). FTC is typically divided into two groups: passive and active (J \& X 2012). Passive control uses different robust control methodologies to address the problem of faults with only a single controller. On the other hand, active control usually includes a fault detection and isolation (FDI) unit in addition to estimating one or more fault parameters and actively tuning the control signal based on fault conditions. Here, FDI is used to identify the plant condition and send the required commands to the plant accordingly. While passive FTC would be restricted to the intersections of solutions for all cases. Hence, while the closed-loop performance by a passive FTC is limited (even for the no fault case), the system works with its best possible performance for different cases under an active FTC. Simplicity in design and implementation of the passive controllers is its main advantage, whereas active FTC is characterized through superior performance. However, the main drawback of passive FTC is the fact that, similar to any other robust control technique, the general solution is only available when the local solutions intersect. Where, it has been shown that active FTC is able to handle the non-intersecting case. Despite the fact that FTC is widely used in different applications, it is relatively unexplored within the WT field of study. Much of the work in this field focuses on FDI techniques (W et al. 2011)-(P \& V 2011) and is based on the first WT fault tolerant benchmark model presented in (A \& P 2011). Few instances have been reported on WT FTC (C \& J 2011),(A. F et al. 2012) and (A. F et al. 2012). However, as discussed in (C \& M 2011), it is desired for WTs to keep working under faulty conditions, which further justifies the need to investigate the FTC techniques for WTs. 


\section{Conclusion}

In this paper we explained briefly of modern turbine control and taking the recent improvement of active power control (APC) established wind turbine control energy systems. As wind energy come to an end to extent higher diffusion levels, the way to make the wind energy and the turbine plan more adaptable to deal with grid frequency variation becoming more significant. Quite a lot of European transmission system operators in realms like Spain, Denmark and Ireland now need to have many system to make the adaption more flexible and easy between the wind plan and the grids, the goal of using wind plants to support in parameter of grid frequency.. This service could be useful even in areas without high diffusion levels, as earlier research proposes; grid frequency robustness can be improved by level a small number of wind turbines given that frequency regulation services. Current research examines the possibility of applying an ancillary market for these ruling capabilities, as this type of advertise could possibly increase the economic capability of wind energy resources. If it is probable for wind plant operators to deliver the services necessary for grid regulation without considerably increasing fatigue destruction to the turbines or other turbine budgets, like $O \& M$, then wind energy might be observed as an enabling supply for grid regulation purposes, supporting in wind energy diffusions higher than $20 \%$. While wind turbine builders have settled the capabilities to meet the desires set by European transmission system operators, ongoing study is being executed to find the full abilities of wind turbine by using different way but everyone from these way have weak sides. Several procedures have existed in literature for given that the different forms of regulation however, more research on such methodologies is required. Areas of benefit for future research contain growth of controllers that achieve more rapidly response times to changing power loads, integration of controllers planned for inertial and secondary regulation, and optimal contribution by wind plants over all regulation phases. Other field of further research includes growth of strategies to balance aggressive power control in contrast to increased actuator usage and structural loads, and studying into the potential connection of active power control loops and conventional turbine control loops. Study into these fields can be increased by simulations that demonstrate, for example, the ability of a controller to offer one or all of the traditional abilities while not stopping pre-existing turbine controllers from keeping turbine safety and reducing fatigue and extreme loading. In this paper we explain many ways to deal with many problems like the weather behavior, advantage and dis advantage of ways and type of the modern wind energy.

\section{References}

A, H. (1952). Statistical theory with engineering applications. New York: Wiley.

A, K., \& K., S. (2010). Simulating Feedback Linearization Control of Wind Turbines Using High-order Models. Wind Energy, 13(5), 419-432.

A, M., S, N., \& J, V. (2007). Combined analytical/FEA-based coupled aero structure simulation of a wind turbine with bend-twist adaptive blades. Renewable Energy, 32(6), 916-930.

A, O., \& P, S. (2011). Wind Turbine Fault Detection Using Counter-Based Residual Thresholding. In 18th IFAC World Congress Milano. Italy.

A, S., P, F., L, F., \& F, B. (2013). Field Testing LIDAR Based Feed-Forward Controls on the NREL Controls Advanced Research Turbine. In Proc. of AIAA Aerospace Sciences Meeting. USA.

A, W. (2004). Modern Control Design for Flexible Wind Turbines. National Renewable Energy Lab., Golden, CO, NREL/TP-500-35816. National Renewable Energy Lab., Golden, CO, NREL/TP-500-35816.

A, W., \& L, F. (2008). Advanced control design for wind turbines; Part I: control design, implementation, and initial tests. National Renewable Energy Lab., Golden, CO, NREL/TP-500-42437, 2008.

A. D, W. (2004). Modern Control Design for Flexible Wind Turbines.

Administration, U. S. E. I. (2011). Renewable energy consumption and electricity preliminary statistics 2010. Washington, DC.

Anca D., H., \& Lov, F. (2009). Review of Contemporary Wind Turbine Concepts and their Market Penetration. Wind Engineering, 28(3), 247-263.

Arnaltes, S. (2003). Comparison of Variable Speed Wind Turbine Control Strategies. In the International Conference on Renewable Energies and Power Quality (pp. 1-6). Vigo, Spain, Apr. 2003.

B, B., \& Ali, A. (2008). Sliding Mode Power Control of Variable Speed Wind Energy Conversion System,. IEEE Transactions on Energy Conversion, 23(2), 551-2008. 
B, B., \& H, S. (2005). Nonlinear Control of Variable Speed Wind Turbines without wind speed measurement. In 44th IEEE Conference on Decision and Control and European Control Conference (pp. 3456-3461). Spain.

B, B., L, L., H, S., \& M, H. (2007). Multivariable control strategy for variable speed variable pitch wind turbine. Renewable Energy, 32(8), 1273-1287.

B, M., \& W, B. (2000). Fuzzy structural analysis using a-level optimization. Computational Mechanics, 26(6), $547-565$

B.k, S. (2011). Valuing the greenhouse gas emissions from nuclear power. A Critical Survey, Energy Policy, 36, 2940-2953.

Beltran, B., \& Ahmed, A. (2009). High-Order Sliding-Mode Control of Variable-Speed Wind Turbines. IEEE Transactions on Industrial Electronics, 56(9), 3314-3321.

Boukhezzar, B., L., L., \& H, S. (2010). Comparison Between Linear and Nonlinear Control Strategies for Variable Speed Wind Turbine Power Capture Optimization. Control Engineering Practice, 18(4), 1357 -1368 .

Boukhezzar, B., \& Siguerdidjane, H. (2005). Nonlinear Control of Variable Speed Wind Turbines for Power Regulation. In Proc. of the IEEE Conference on Control Applications (pp. 28-31). Canada.

C, R. (n.d.). La Recherche Aerospatiale. In Numerical calculation of three-dimensional unsteady flows with vortex sheets (pp. 289-298).

C, S., \& J, S. (2011). Robust and Fault-Tolerant Linear Parameter- Varying Control of Wind Turbines. Mechatronics, 21(4), 645-659.

C, S., \& M, N. (2011). Automated Design of an FDI-System for the Wind Turbine Benchmark. In 18th IFAC World Congress Milano. Italy.

Cacuci, \& Cacuci, L.-B. (2004). A comparative review of sensitivity and uncertainty analysis of large scale systems - II. Nuclear Science and Engineering, 147(3), 204-217.

D, D., \& H, P. (1985). A review of fuzzy aggregation connectives. Information Sciences, 36(1-2), 85-121.

De, O., \& Vries. (1983). Aerodynamic aspects of wind energy conversion. In Fluid Mech (1st ed., pp. 77-96).

Dodson, L., \& Busawon, K. (2005). Estimation of the power coefficient in a wind conversion system. In Proc. of the 44th IEEE Conference on Decision and Control and the European Control Conference. Spain.

E, B., \& A, T. (2002). Optimal design of horizontal axis wind turbines using blade element theory and evolutionary computation. Journal of Solar Energy Engineering, 124(4), 357-363.

E, M., T, S., N, U., \& A, Y. (2007). Robust Predictive Control of Variable-Speed Wind Turbine Generator by Self-Tuning Regulator. In Proc. of IEEE Power Eng. Soc. Gen. Meeting (pp. 1-8).

E, S., \& L, P. (2013). Reducing Lidar Wind Speed Measurement Error with Optimal Filtering. In Proc. American Control Conference (pp. 621-627).

Energy, D. of. (2008). 20 \% Wind Energy by 2030: Increasing Wind Energy's Contribution to U.S. Electriclty Supply.

Energy, U. S. D. of. (2008). Energy efficiency and renewable energy. Springfield, VA.

EOLOS Wind Energy Research Consortium. (n.d.). Retrieved from http://www.eolos.umn.edu/

F, A., C, S., \& J, S. (2012). Structured Linear Parameter Varying Control of Wind Turbines. In Springer-Verlag Berlin Heidelberg (pp. 303-337).

F, B., \& R, M. (2004). Control of Variable-Speed Wind Turbines by LPV Gain Scheduling. Wind Energy2, 7(4), $1-8$.

F, D., D, S., L, P., \& A, W. (2012). Comparison of Two Independent Lidar-Based Pitch Control Designs. In roc. of AIAA Aerospace Sciences Meeting. USA.

F, D., L, P., \& A, W. (2010). Combining Standard Feedback Controllers with Feedforward Blade Pitch Control for Load Mitigation in Wind Turbines. In Proc. of AIAA Aerospace Sciences Meeting. USA.

Fingersh, L., \& Wright, A. (2008). Advanced Control Design for Wind turbines Part I: Control Design. 
Freeman, J., \& Balas, M. (n.d.). An Investigation of Variable-Speed Horizontal-Axis Wind Turbines Using Direct Model-Reference Adaptive Control. In Proceedings of AIAA/ASME Wind Energy Symposium,. Reno, NV.

G, B., \& R, D. (1985). A review of some methods for ranking fuzzy subsets. Fuzzy Sets and Systems, 15(1), $1-19$.

G. H, C., \& K, P., K. (n.d.). Vortex methods theory and practice. Cambridge, UK: Cambridge University Press.

H, G., \& G, Y. (2010). Output Power Control for Variable-Speed Variable-Pitch Wind Generation System. IEEE Trans. Energy Conversion, 25(2), 494-503.

H, L., Z, C., \& J. K, P. (2006). Optimal power control strategy of maximizing wind energy tracking and conversion for VSCF doubly fed induction generator system (pp. 1-6). Shanghai: CES/IEEE 5th International Power Electronics and Motion Control Conference.

H, N., \& D, T. (2009). Fault-Tolerant Control Systems Fault-tolerant Control Systems: Design and Practical Applications. Springer,.

H, T., H, C., K, S., \& T, I. (2009). Pitch Angle Control of Wind Turbine Generator Using Less Conservative Robust Control,. In 18th IEEE International Conference on Control Applications.

H.J, Z. (2011). Fuzzy set theory and its application. London: Kluwer-Academic Publishers.

H. M, N., \& K.Y, M. (2000). No Title. Optimization Model for Rotor Blades of Horizontal Axis Wind Turbines, 74(6), 649-666.

HSBC Global Research. (2011). Japan's nuclear crisis and the case of clean energy. Canary Wharf, UK.

J, A., A, B., J, L., P, F., \& Y, J. (2012). Tutorial of Wind Turbine Control for Support- ing Grid Frequency through Active Power Control. In Proceedings of the American Control Conference (pp. 3120-3131).

J, J. (2007). Modeling and Loads Analysis of an Offshore Floating Wind Turbine,. National Renewable Energy Lab, Golden, CO.

J, J., \& X, Y. (2012). Fault-tolerant control systems: A comparative study between active and passive approaches. Annual Reviews in Control, 36(1), 60-72.

J, L., L, P., \& E, S. (2011). Model Predictive Control Using Preview Measurement from LIDAR. In Proc. of AIAA Aerospace Sciences Meeting. USA.

Johnson, K. (2007). Adaptive Torque Control of Variable Speed Wind Turbines. NREL/TP-500-36265.

Johnson, K., Pao.L, Balas, M., \& Fingersh, L. (n.d.). Control of Variable-Speed Wind Turbines: Standard and Adaptive Techniques for Maximizing Energy Capture. IEEE Control Systems Magazine, 26(3), 70-81.

Joshnson, K. E., \& Fingersh, L. (n.d.). Adaptive Pitch Control of Variable-Speed Wind Turbines. J. Solar Energy Eng, 130(3), 031 012-1 - 031 012-7.

K, H., K, M., \& G, E. (2010). "LIDAR Wind Speed Measurement From a Rotating Spinner,. In European Wind Energy Conference and Exhibition. Poland.

K, J. C. D., P. P, G., \& Francis, B. (1989). State Space Solutions to Standard H2 and H1 Control Problems. IEEE Trans. Automatic Control, 34(8), 831-847.

K, J., L.Y, P., M., B., \& L, F. (2006). Control of variable- speed wind turbines: standard and adaptive techniques for maximizing energy capture. Control Systems, IEEE, 26(3), 70-81.

K, S. (2003). Disturbance Tracking and Blade Load Control of Wind Turbines in Variable Speed Operation. National Renewable Energy Lab. Golden, CO, NREL/CP-500-33011.

K, S., \& M, B. (2003). Periodic Disturbance Accommodating Control for Blade Load Mitigation in Wind Turbines. Journal of Solar Energy Engineering, 3(125), 379-385.

K. Y, M., \& M, H. N. (2002). Optimal frequency design of wind turbine blades. Journal of Wind Engineering and Industrial Aerodynamics, 90(8), 961-986.

K.O, M. (1990). Sciences, applied probability and stochastic process in engineering and physical. New York: Wiley-Inter science.

Kumar, A., \& Stol, K. (2008). Simulating MIMO Feedback Linearization control of Wind Turbines Using FAST. In Proceedings of AIAA/ASME Wind Energy Symposium. Orlando, FL. 
L, M., \& S. S, R. (2009). Interval-based multi-objective optimization of aircraft wings under gust loads. AIAA Journal, 47(6), 563-575.

L, P. (1919). Appendix to wind turbines with minimum energy losses. Betz A, Goettenger News.

L, P., \& K, O. (2009). A Tutorial on the Dynamics and Control of Wind Turbines and Wind Farms. In Proc. of American Control Conference (pp. 2076-2089).

L.A, Z. (1965). Fuzzy sets. Information and Control, 8(3), 338-353.

M, B., K, M., \& S, F. (2013). Adaptive Disturbance Tracking Theory with State Estimation and State Feedback for Region II Control of Large Wind Turbines. In American Control Conference. USA.

M, B., M, K., \& M, S. (2006). Diagnosis and Fault-Tolerant Control. pringer-Verlag.

M, B., \& Q, L. (2010). Adaptive Disturbance Tracking Control for Large Horizontal Axis Wind Turbines in Variable Speed Region II Operation. In 48th AIAA Aerospace Sciences Meeting Including the New Horizons Forum and Aerospace Exposition. USA.

M, G. S. (2004). Quantitative Robust Control Engineering: Theory and Experimental Results on Wind Turbines. In Plenary Session. 2nd International Conference on Renewable Energy and Power Quality. Spain.

M, G. S., \& J, E. (2008). Beyond the Linear Limitations by Combining Switching and QFT: Application to Wind Turbines Pitch Control Systems. International Journal of Robust and Nonlinear Control, 19, 40-58.

M, H. (1999). Variable-Speed Wind Turbine Controller Systematic Design Methodology: A Comparison of Nonlinear and Linear Model-Based Designs. National Renewable Energy Lab., Golden, CO, NREL/TP-500-25540.

M, I., \& M, S. (1995). A possibilistic linear program is equivalent to a stochastic linear program in a special case. Fuzzy Sets and Systems, 76(22), 309-331.

M, M., H, N., \& N, P. (2011). DK -Iteration Robust Control Design of a Wind Turbine. In IEEE International Conference on Control Applications (pp. 1493-1498). USA.

M, S., O, M., \& D, W. (2010). Multiple Model MIMO Predictive Control for Variable Speed Pitch Wind Turbines. In American Control Conference (pp. 2778-2784). USA.

M, Bilal, A. (1997). Uncertainty modeling and analysis in civil engineering. Boca Raton, Florida: CRC.

M. B, B. (1987). Water quality modeling: A review of the analysis of uncertainty. Water Resource Research, 23(8), 1393-1442.

M., E., \& I, C. (1992). Doubly-output induction generator operating at subsynchronous and supersynchronous speeds. IEE Proceedings B, 139(5), 429-442.

M., H., A., H., Larsen T., O. S., P., S., \& Fuglsang, P. (2005). Control Design for a Pitch-regulated Variable-speed Wind Turbine Report\# Riso-R-1500(EN). Riso National Laboratory. Roskilde, Denmark.

M. C. B., N. M. R., \& E. Hale. (2010). Wind Flow Modeling Uncertainty. In AWS Trupower. Albany, NY.

M. G. M., \& J. M. G. A. (2011). Technical and regulatory exigencies for grid connection of wind generation, wind farm-technical regulations, potential estimation and siting assessment. Gastón O. Suvire.

Mathworks, T. R. (n.d.). Wind Turbine Doubly-Fed Induction Generator (Phasor Type). Retrieved from www.mathworks.com

Muljadi, E., \& Buttereld, C. P. (2000). Pitch Controlled Variable Speed Wind Turbine Generation. Golden, CO, Feb. 2000: National Renewable Energy Laboratory.

Muljadi, E., K, P., \& Migliore, P. (2000). Soft-stall control for variable-speed stall-regulated wind turbines. Journal of Wind Engineering and Industrial Aerodynamics, 85(3), 277-291.

N, W. (2013). LIDAR-assisted Feedforward and Feedback Control Design for Wind Turbine Tower Load Mitigation and Power Capture Enhancement. Colorado School of Mines.

N, S., B., D, K., \& S, B. (2005). Wind electrical systems. New Delhi, India: Oxford University Press.

N.U, P. (2007). Process, Stochastic. In World Scientific. Singapore.

Oce, E. A., \& Energy, D. of. (2002). Analysis of Levelized Historical Wind Energy Cost Trends. National Renewable Energy Laboratory. 
P, F., \& H. A. M. (1999). Optimization method for wind turbine rotors. Journal of Wind Engineering and Industrial Aerodynamics, 80(1), 191-206.

P, I., \& J, S. (1996). Robust Adaptive Control. Prentice Hall.

P, K., \& S., W. W. (1994). Stochastic programming (Second edi.). Wiley, Chichester.

P, N., \& V, P. (2011). Fault Detection and Isolation of a Real Wind Turbine using LPV Observers. In 18th IFAC World Congress Milano (pp. 12372-12379). Italy.

P. A, B., \& G, D. (2007). Parametric Modeling of Large Wind Turbine Blade. In Abaqus UK Regional User Meeting (pp. 221-225). UK.

Pao, L. Y., \& K. E, J. (2011). Control of Wind Turbines. In Proc. of AIAA Aerospace Sciences Meeting (Vol. 31, pp. 44-62). USA.

R, F., \& M, B. (2000). Direct Adaptive Rejection of Persistent Disturbances. Journal of Mathematical Analysis and Applications, 251(2), 28-39.

R, L., \& M, M. (2009). Optimal wind turbine design to maximize energy production. Power and Energy (Vol. 223, pp. 93-101).

R, S., T, S., T, K., \& N, U. (2004). Output Power Leveling of Wind Turbine Generato by Pitch Angle Control Using Adaptive Control Method. In International Conference on Power System Technology (pp. 834-839). Singapore.

R, W., \& J, B. (2012). No Titlewind technologies market report. Tech. Rep. August, U.S. Department of Energy, 2012.

R. S, A., \& R. J, M. (2009). CFD analysis on aerodynamic design optimization of wind turbine rotor blades. World Academy of Science, Engineering and Technology, 60(4), 71-75.

R. E. W., \& P. B, L. (1976). Aerodynamic performance of wind turbines. Oregon: Oregon State University, Corvallis.

R. M. T. (1977). A control engineering review of fuzzy systems. Automatic, 13(6), 559-569.

REN21. (2011). Renewable Energy Policy Network for the 21st Century. paris.

S, F., M, B., \& A, W. (2009). Direct Adaptive Control of a Utility-Scale Wind Turbine for Speed Regulation. International Journal of Robust and Nonlinear Control, 19(1), 59-71.

S, F., S, B., \& A, W. (2011). Generator Speed Regulation in the Presence of Structural Modes through Adaptive Control using Residual Mode Filters. FAC Journal ofMechatronics, 21(4), 660-667.

S, M. (2006). Wind energy fundamentals, resource analysis and economics. In Wind energy fundamentals, resource analysis and economics. Springer, Malapuram, Kerala, India.

S, M., B, I., H., \& E, D., K. (2008). A methodology for preforming global uncertainty and sensitivity analysis in system biology. J. Theor. Biol, 254(1), 178-196.

S, T., \& N, P. (2007). A Disturbance Decoupling Nonlinear Control Law for Variable Speed Wind Turbines. In Proc. of the 15th Mediterranean Conference on Control and Automation. Greece.

S. S, I. (1999). Uncertainty analysis of transport transformation models. Rutgers: The State University of New Jersey.

S.M, H., \& I.A, S. (2000). ), Load design, testing and manufacturing of small mixed airfoil wind turbine blades of glass fiber reinforced plastic Part II. Energy Conversion \& Management, 41(3), 249-280.

S. S, R., \& L.T, C. (2001). Fuzzy boundary element method for the analysis of imprecisely defined system. AIAA Journal, 39(9), 1788-1797.

Sanz, M, G., \& J, E. (2008). Beyond the Linear Limitations by Combining Switching and QFT: Application to Wind Turbines Pitch Control Systems. International Journal of Robust and Nonlinear Control, 19(5), 0-58.

Soliman, M., Malik, O., \& Westwick, D. (2010). Multiple Model MIMO Predictive Control for Variable speed Variable Pitch Wind Turbines. In Proceedings of 2010 American Control Conference,. Baltimore.

Song, Y., Dhinakram, B., \& Bao, X. (n.d.). Variable Speed Control of Wind Turbines using Non-linear and Adaptive Algorithms. J. Wind Eng. and Ind. Aerodynamicsl, 85(3), 293-308. 
Sorensen, \& N, J. (2001). Aerodynamic aspects of wind energy conversion. In Annual Review of Fluid Mechanics (1st ed., pp. 427-448).

T, S., R, S., \& N, U. (2006). Output Power Leveling of Wind Turbine Generator for All Operating Regions by Pitch Angle Control. IEEE Transactions on Energy Conversion, 21(2), 67-475.

V, R., \& F, A. (2013). Robust Adaptive Fault Tolerant Pitch Control of Wind Turbines. Wind Engineering Journal.

W, C., S, D., \& A, H. (2011). Observer-Based FDI Schemes for Wind Turbine Benchmark. In 18th IFAC World Congress Milano (pp. 7073- 7078).

W. D, W., \& S. S, R. (2004). Interval approach for the modeling of tolerances and clearances in mechanism analysis. Journal of Mechanical Design, 126(4), 581-592.

Wijk, V., M, A., C, J. P., \& Coelingh. (1993). Wind power potential in the OECD countries.

Wright, A. (2000). The Design of Closed Loop Controllers for Wind Turbines. Wind Energy, 3(5), 149-163.

Wright, A., Fingersh, L., \& Stol, K. (2007). Design and Testing Controls to Mitigate Tower Dynamic Loads in the Controls Advance Research Turbine.

Z, C., J. M, G., \& F, B. (2009). A review of the state of the art of power electronics for wind turbines. IEEE Transactions On Power Electronics, 24(8), 1859-1875.

\section{Copyrights}

Copyright for this article is retained by the author(s), with first publication rights granted to the journal.

This is an open-access article distributed under the terms and conditions of the Creative Commons Attribution license (http://creativecommons.org/licenses/by/3.0/). 